\title{
معايير تصميم الفراغات العمرانية في التجمعات السكنية المغلقة دراسة تحليلية \\ Standards of Design of Urban Spaces in Residential Gated Compounds Analytical Study
}

م / نورهان محمد عبد السلام رضوان أ.م. د/ طارق مصطفي صبحى أ.م. د/ محمد عبد المجيد دياب المقدمة: المقا: إن الفراغات العمر انية هي التعبير الأقوى عن التصميم العمر اني فهي تعتبر المدخل الرئيسي للتعامل مع هذا لإنها

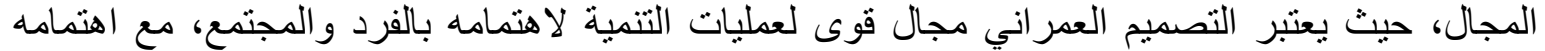

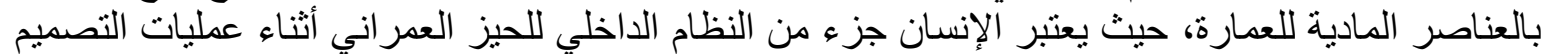
تحت مبدأ تصميم من أجل الإنسان. ملخص:

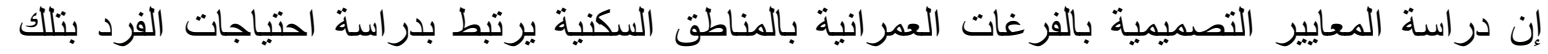

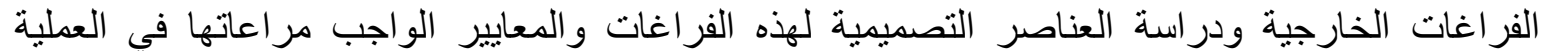

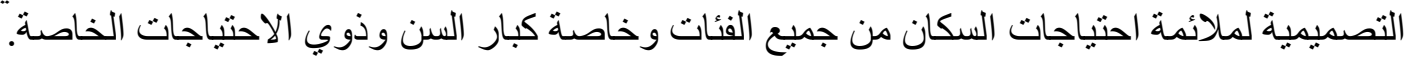

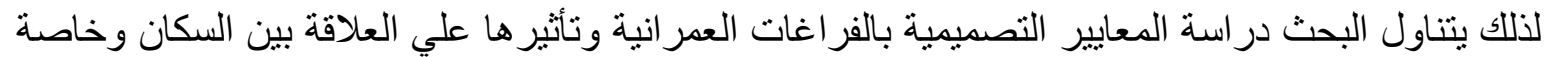

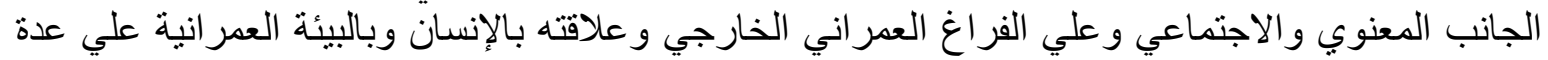
مستويات للوصول لإطار عام وتفصيلي يساهم في عملية تصميم الفراغات الات العمر انية الخارجية ويخدم عملية التصميم العمر اني من أجل تحقيق احتياجات الإنسان الأساسية ونوفير الأنشطة الاجتماعية المناسية الإنية والتأكيد

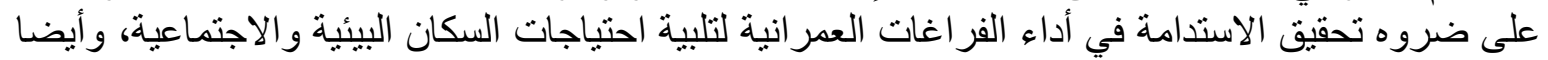

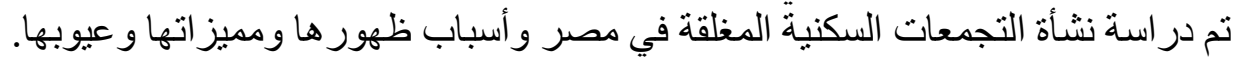

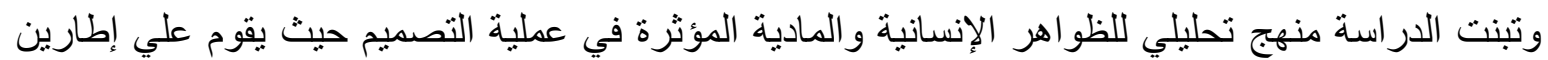

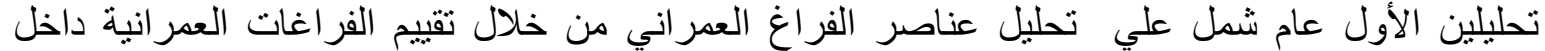

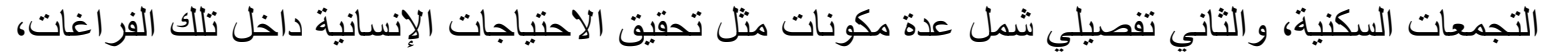

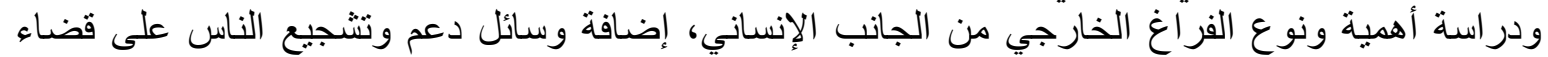

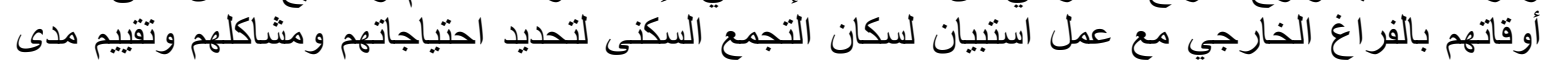
تحقيق ونجاح هذه الفر اغات في تحقيق أهدافها ومن خلال ذلك تم الوصول لنتان لنتائج التحليل و التوصيات. الكلمات الدالة: الفراغات العمرانية ـ احتياجات المستعملين داخل الفراغات العمرانية ـ التجمعات السكنية المخلقة 


\begin{abstract}
:
The study of the design standards in the urban spaces in the residential areas is related to the study of the user's needs in those outdoor spaces and the study of the design elements of these spaces and the standards of design to be taken into the design process

to suit the needs of the user of all levels, especially the elderly and handicapped.
\end{abstract}

Therefore, the research deals with the study of design standards in urban spaces and their impact on the relationship between residents, especially the moral and social aspect, and on the outdoor urban space and its relationship to humans and the urban environment at several levels to reach a general and detailed frame that contributes to the process of designing external urban spaces and serves the urban design process in order to achieve basic human needs and provide social activities and achieve sustainability in the urban spaces to achieve the environmental and social needs of the population. The study includes beginning of closed residential communities in Egypt and the reasons for their emergence, their advantages and disadvantages.

The study adopted an analytical approach to the human and material phenomena in the design process, which is based on two analytical frameworks. The first is general, which includes the analysis of the elements of the urban space by evaluating the urban spaces within the residential communities, and the second, a detailed approach several components such as achieving human needs within those spaces, and studying the importance and type of external space, the human aspect, adding the means of supporting and encouraging people to spend their time in the outdoor space with a questionnaire for the residents of the residential complex to find out the extent of the achievement and success of these investigations in achieving their goals, and through that access to the achievement and recommendations.

\title{
Key words: Urban spaces-User's needs inside urban spaces- Residential gated compounds
}

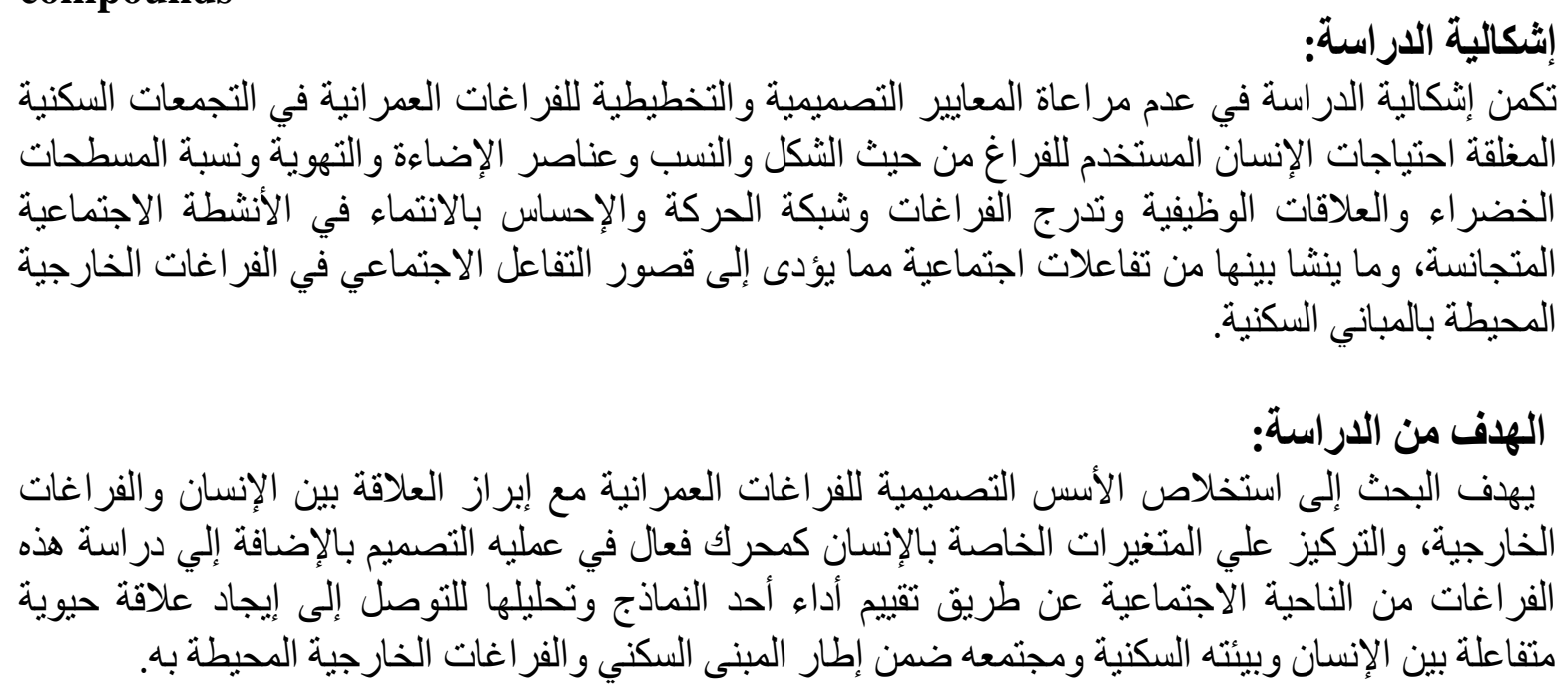


للوصول إلى أهداف البحث تم تقسيم البحث إلي ما يلي: ـ ـ دراسة نظرية الغرض منها الحصول على العيم المعلومات التي تمكننا من الوصول إلى صياغة النموذج التقييمي المقتر ح وتشمل شقين أساسين:

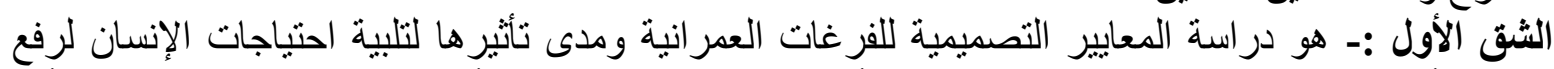

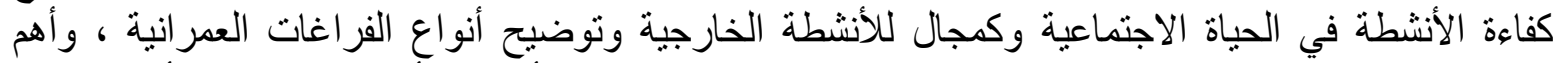

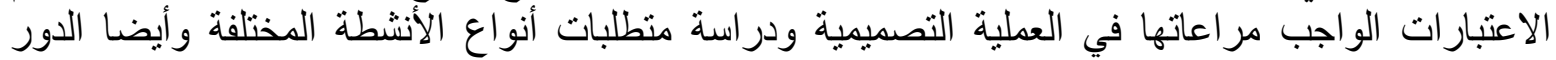

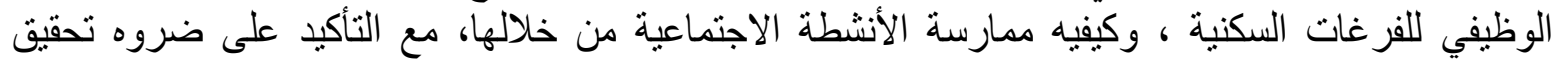

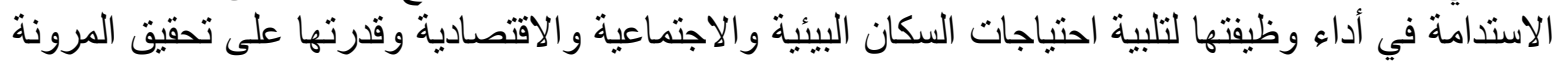

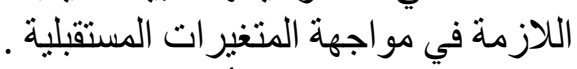

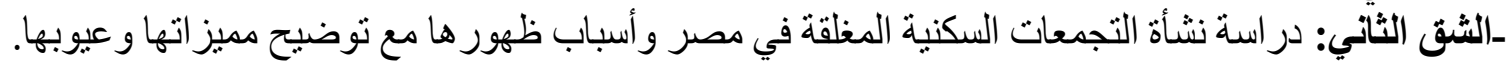

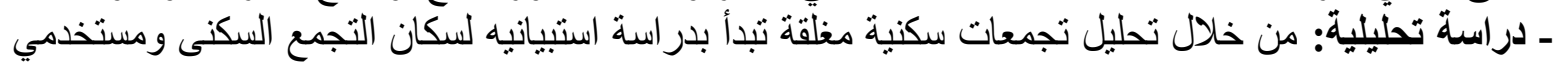

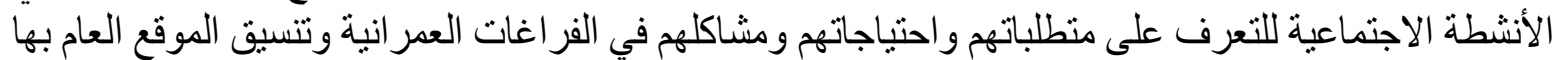

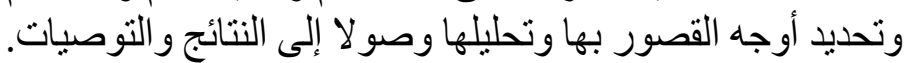

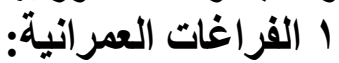

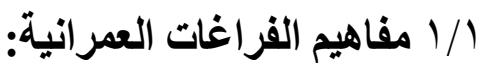
تعددت مفاهيم وتعريفات الفر اغات العمر انية طبقا لتوجهات العبلة العماء مما دفع إلي تحليل هذه التوجهات من خلال

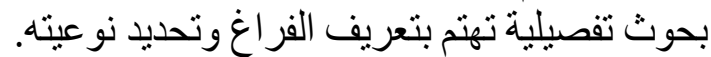

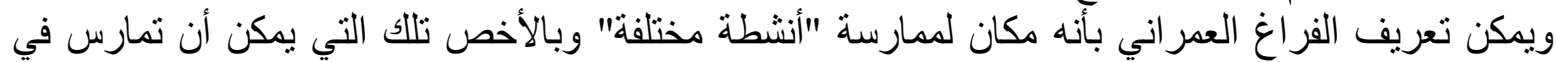

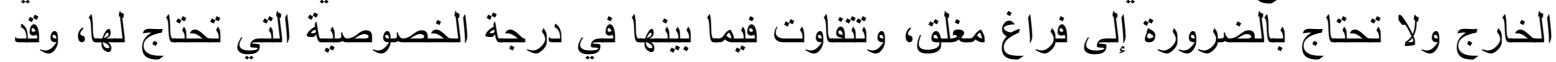

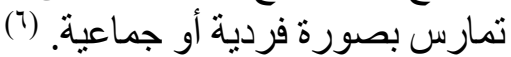
ويعرف أيضا بأنه المكان الذي يحتودي الأشخاص و الأنشطة من خلال أبعاده الثلاثة كما أن له صفة التطور بمرور

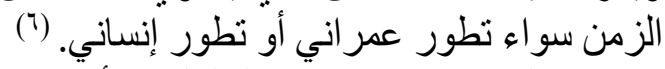

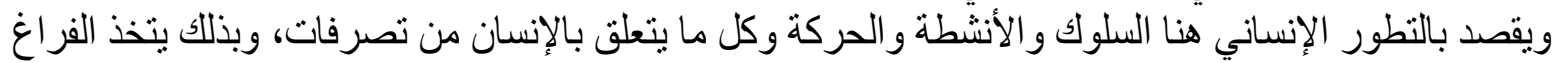

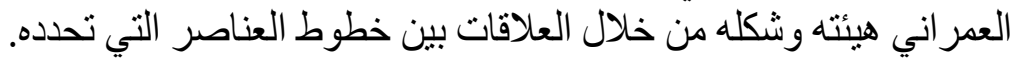

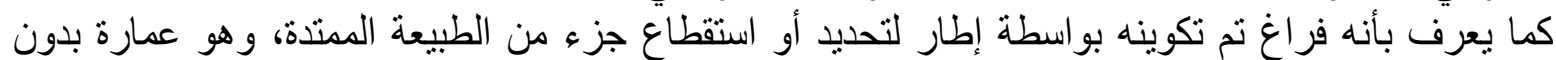

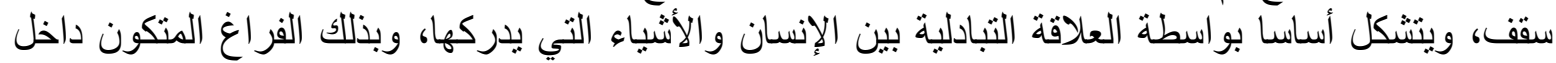

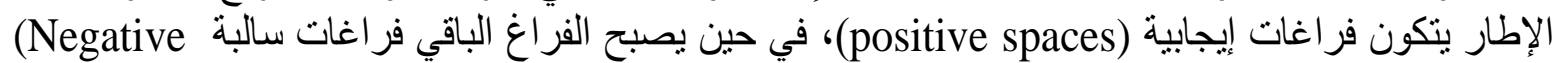
(') . Spaces) إع/اع أنواع الفراغات العمرانية :

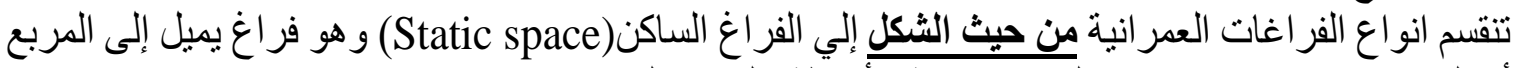
أو الائرة ويوحى بالاستقرار و التجمع و إقامة الآنشطة بالتجمع السكنى.

و الفراغ الديناميكي (Dynamic space) و هو فر اغ خطى يمتد معه البصر إلى نقطة التلاشي المنظورية مما يوحى بالحركة ويرتبط بحركة المشاة و الحركة الألية.

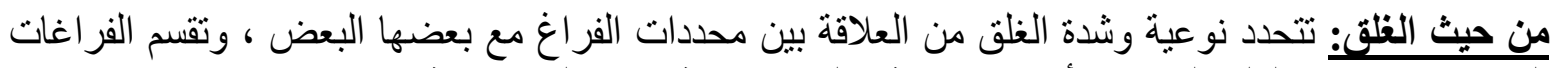

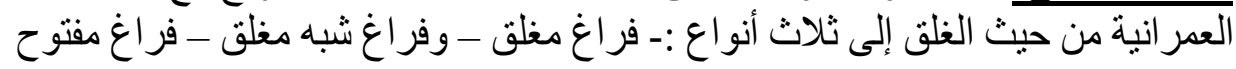

من حيث مستويات التّرج: بمكن تقسيم الفراغات العمر انية من حيث الاستخدام و الوظيفة إلى ثلاث أنواع :

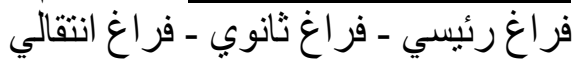


من حيث المستخدمين: لنوعية المتخدمين للفراغات العمرانية تأثير على الفراغ من حيث شكله وطبيعته

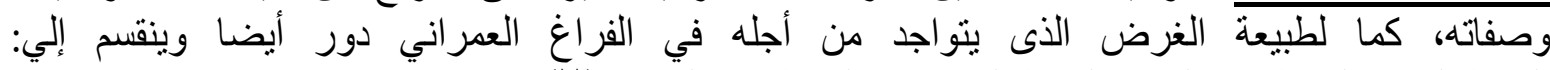

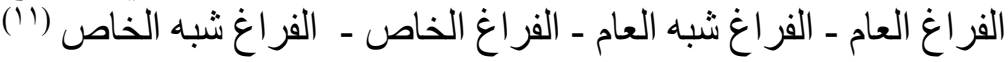

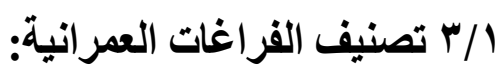

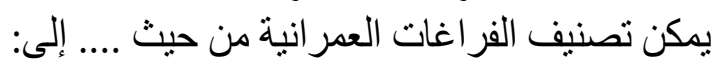

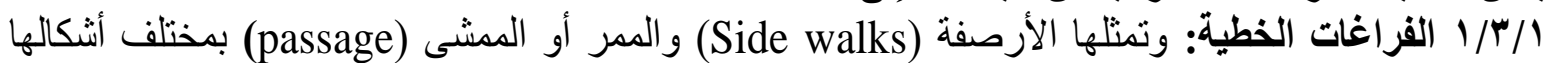

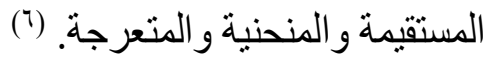

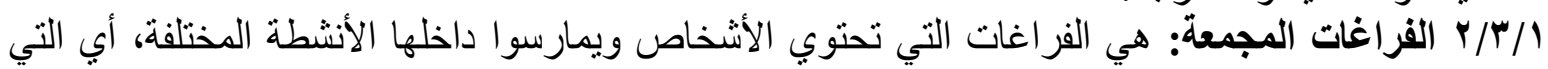

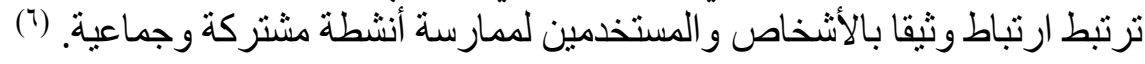

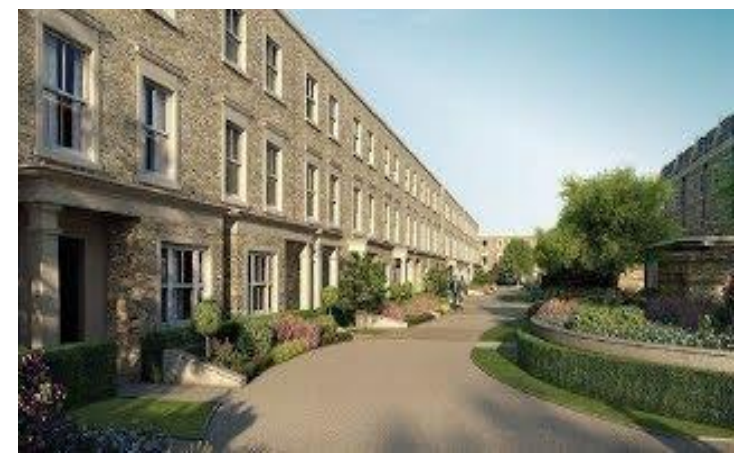

شُكل (r) الممرات كنموذج للفراغ الخطى

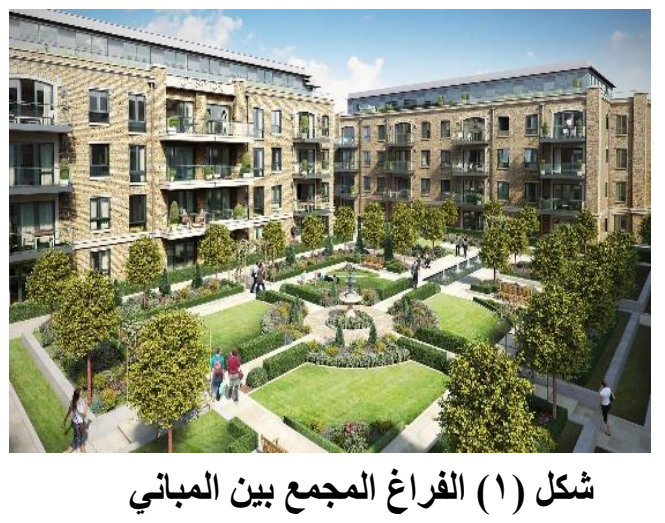

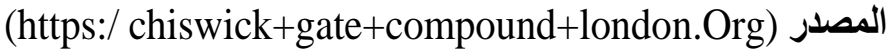

1/ إ / مكونات الفراغات العمرانية:

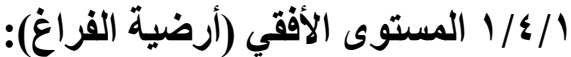

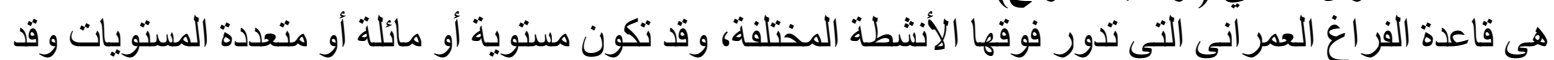

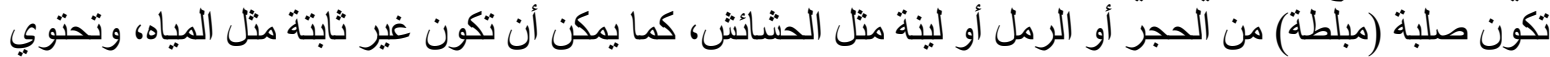

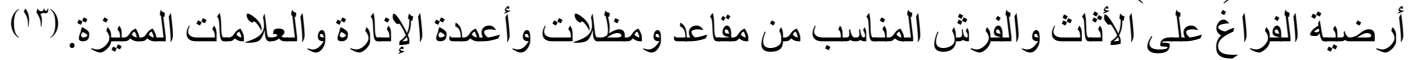

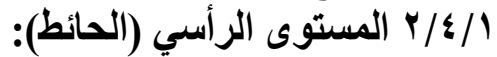
يشكل حائط الفر اغ المستوي الرئرأسي للفر اغ العمر اني ويحدد خصائصده المختلفة ويحدد سعته وتتنوع بين الحيطان

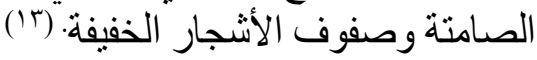
ت تمثل السماء عادة هي سقق الفر اغ في الخارج و أحيانا يكون السقق مغطى او شبه مغطى بالمظلات. شكل (r)

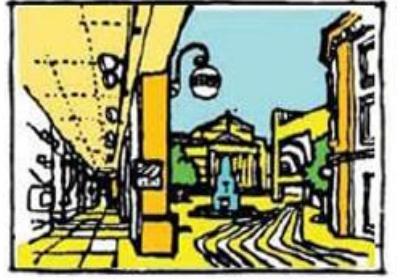

الصررة البصرية المثكاملة للفراغ

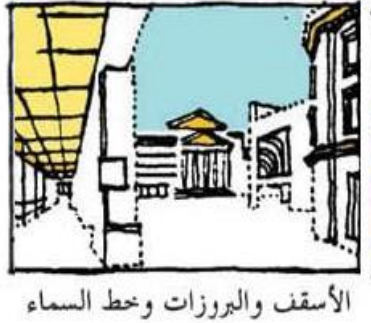

الأسقن والبروزات وخط السماء

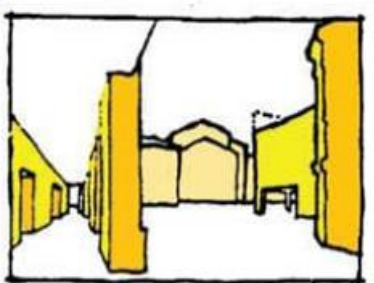

الكتل المددة للفراغ (الحوائط)

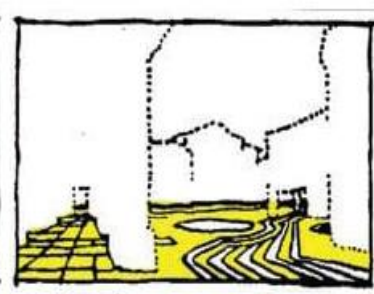

الارضيات (المستوي الأفقي)

شكل (r) مكونات الفراغات العمرانية المصدر (^) 


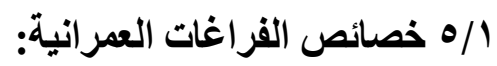

يمكن تحديد خصائص الفر اغات العمر انية من خلال التصنيفات التالية:

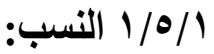

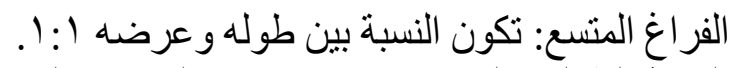

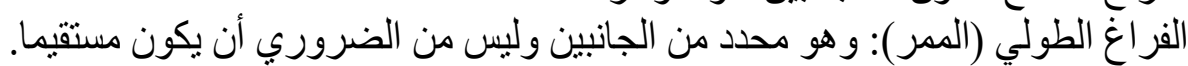

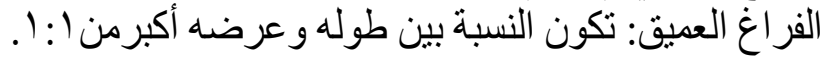

r/0/1

• المقياس الودود: هو فراغ يحقق الاحتو اء ويشجع على التآلف الاجتماعي وتحقيق الخصوصية ويمكن

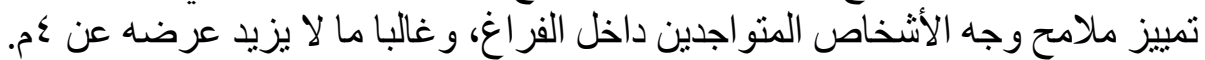

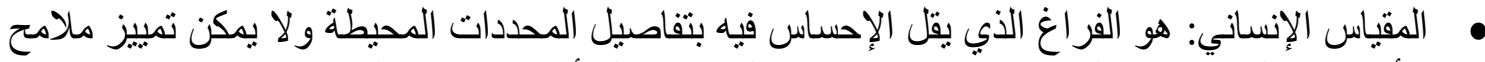

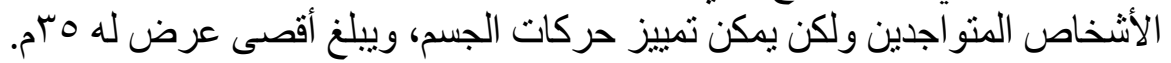

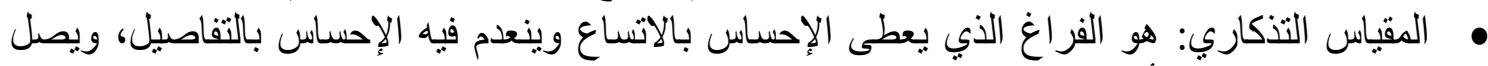

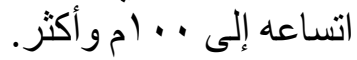

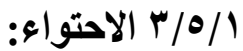

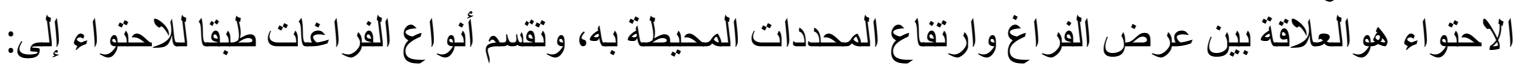

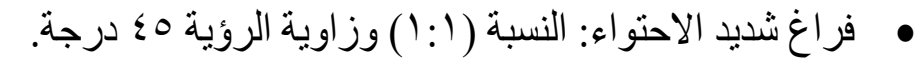

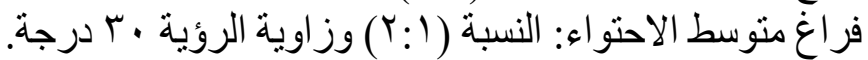

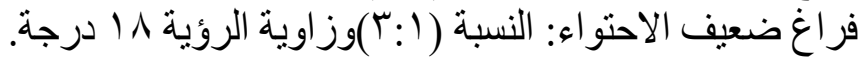

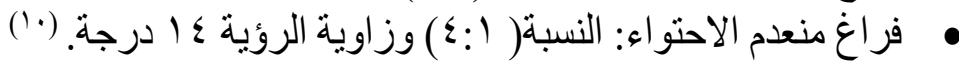

1/1 الأنثطة الإنسانية في الفراغات العمرانية: يمكن تقسيم أنو اع الأنشطة الإنسانية في الفر اغات العزات العمر انية إلى:

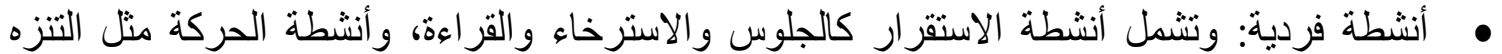

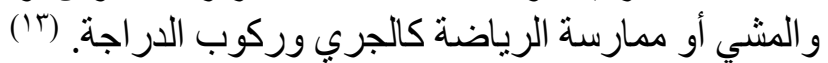

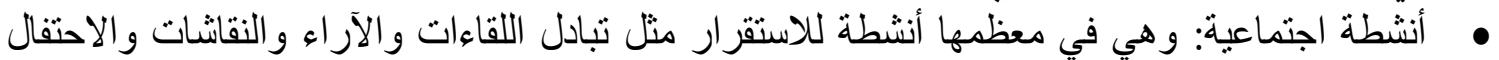

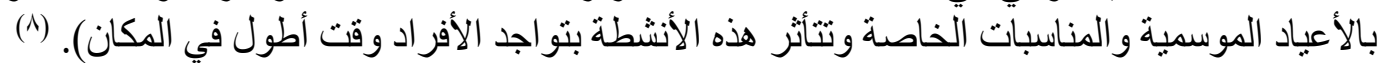

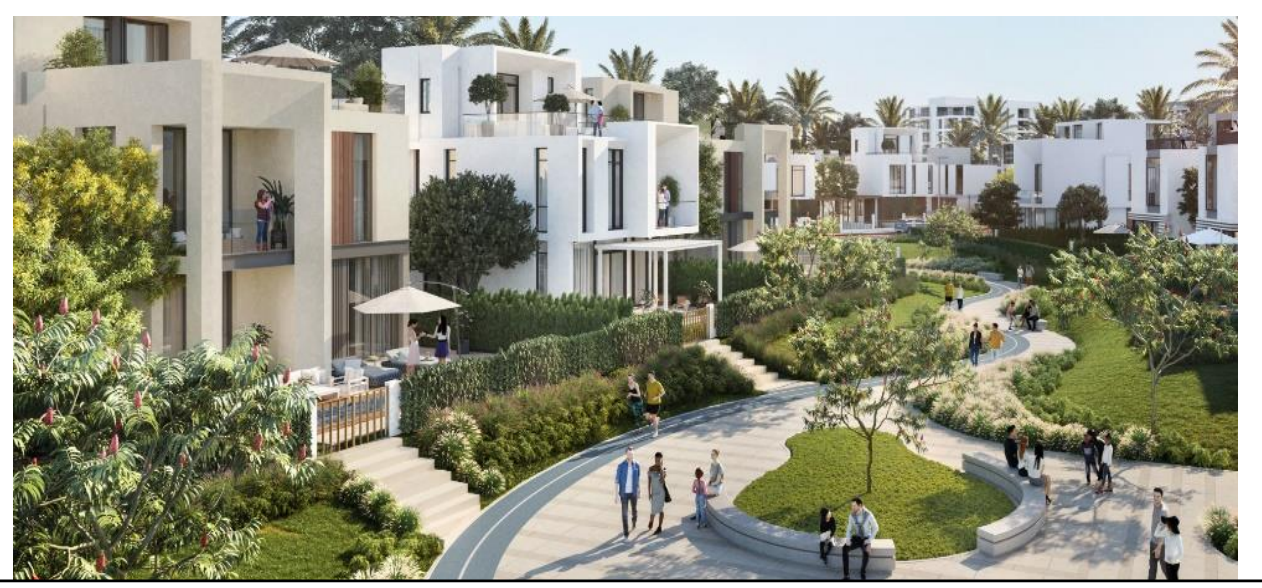

Cairo gate el-Sheikh Zayed شكل (๕) يوضج أنثطة الحركة والاستقرار في الفراغ العمراني

(https:/ Cairo gate el-Sheikh Zayed Compound.Org) المصدر 


\section{v/l الاحتياجات الإنسانية في الفراغات العمرانية:}

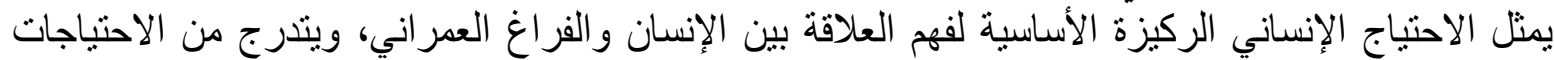

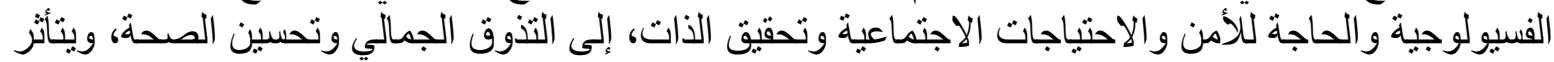

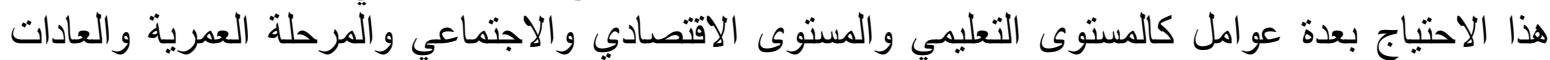

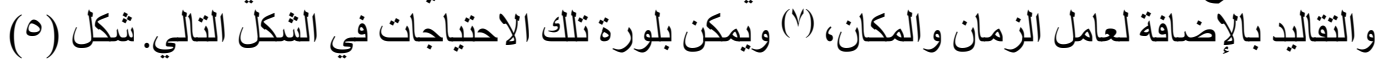

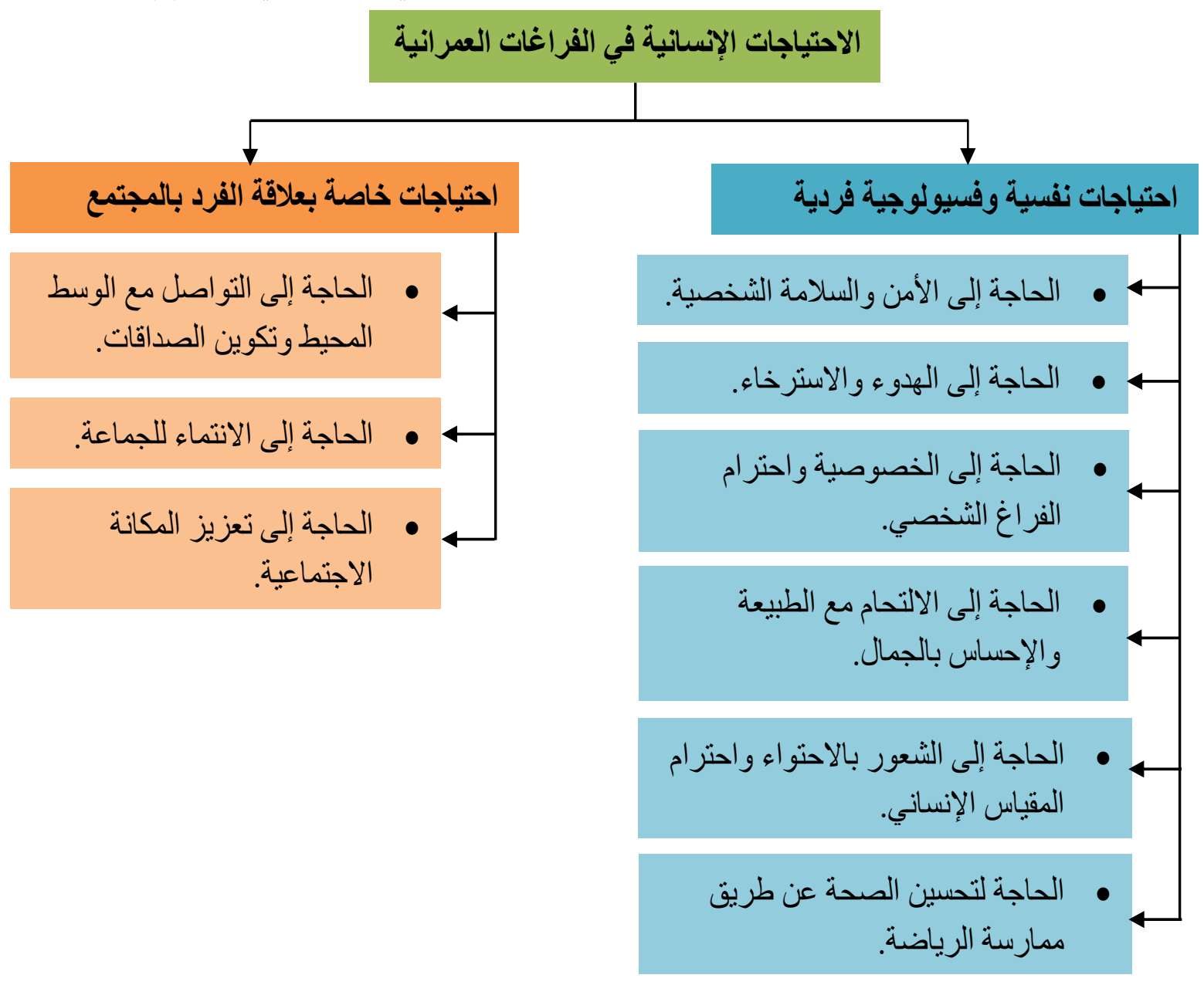

\section{شكل (0) الاحتياجات الإنسانية في الفراغات العمرانية}

1/1 المعايير الواجب مراعاتها في تصميم الفراغات العمر انية داخل التجمعات السكنية:

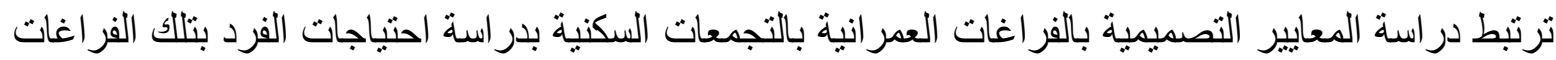

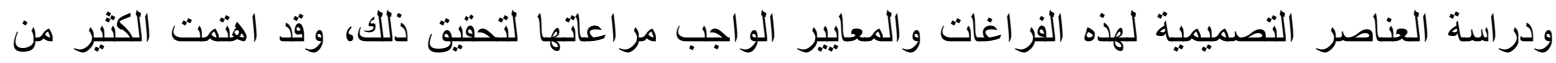

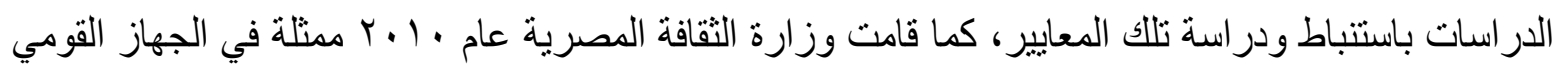

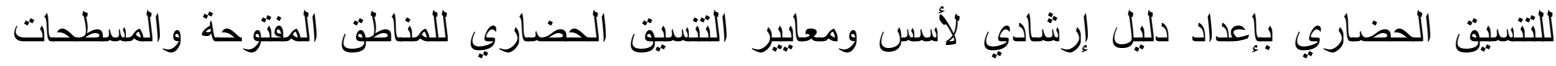

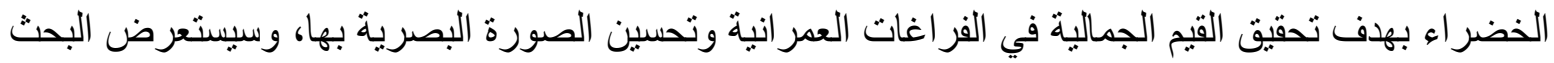
فيما يلي أهم تللك المعايير: 
هجب اختيار موقع مناسب للحديقة بحيث يمكن الوصول إليها من كل المجموعة السكنية ويفضل أن تكون

في موقع متوسط في المجمو عة السكنية. يجب أن تنتاسب المساحة المخصصة للحديقة مع كثافة السكان الذين تخدمه، وأن تتر اوح المساحة بين

1, • • ومץ لكل نسمة.

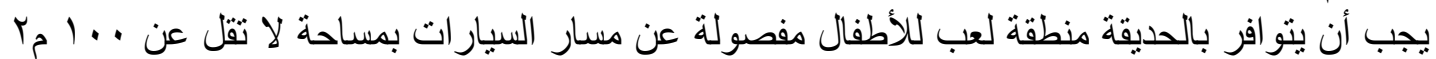

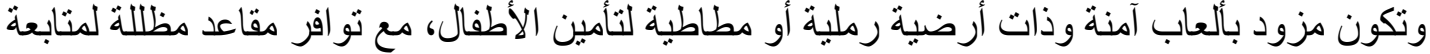

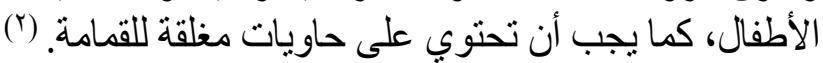

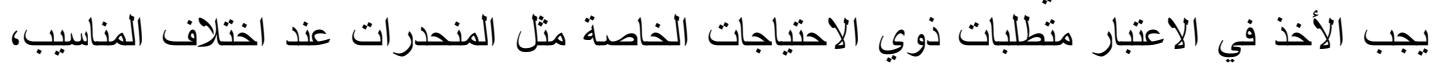

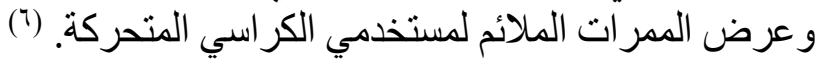

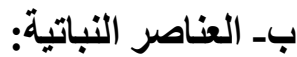

يجب التتوع في العناصر النباتية وضرورة وملاءمتها للوظائف المنوطة بها كالتظليل و التجميل مع تجنب الأشجار متساقطة الأوراق. يجب أن يكون موقع الأشجار والمسافات بينها ملائمة لوجود وتتوع الأنشطة بينها ولتنليل الممرات

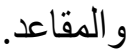

• • استخدام العناصر النباتية للربط بين عناصر الفراغ المختلفة والتأكيد على محاور الحركة. (9)

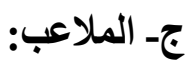
يجب توفير منطقة ترفيهية للبالغين مفصولة عن منطقة لعب الأطفال.

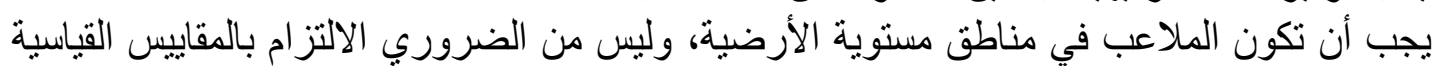

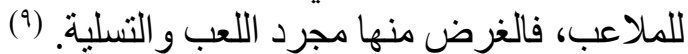

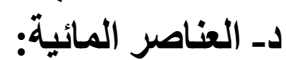
• مراعاة التنوع في العناصر المائية مما يضفي الحيوية على الفراغ مثل النوافير وحمامات السباحة وبحير ات المياه. - مراه مر ماعاة استخدام أرضيات غير قابلة للانزلاق حول العناصر المائية مع مراعاة العمق الملائم لتحقيق

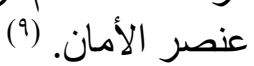

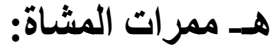

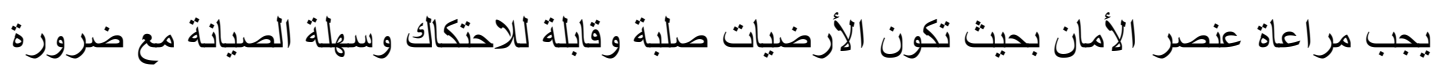
التشجيع على المشي بتظليل الممرات بالعناصر النبات التباتية بقدر الإمكان. يجب استخدام مو اد مختلفة في الأرضيات عند اختلاف الأنشطة مع وجود الختلاف الأنس في اتجاه الحركة لعدم

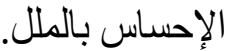
يجب تصميم مقاعد مريحة قريبة من ممرات المشاة للراحة ومن أجل كبار السن.

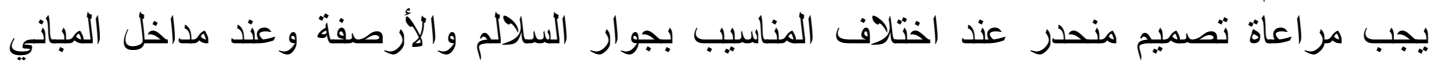
السكنية.

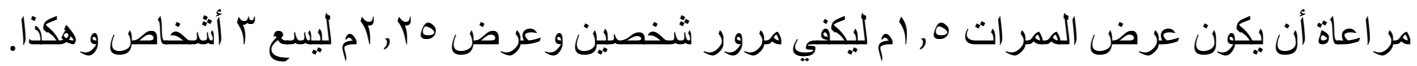

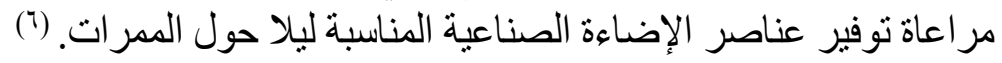

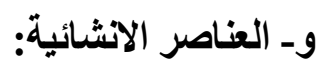

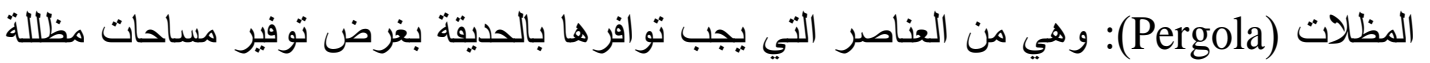
للجلوس و الاسترخاء، ووقد تصنع كاملة من الخشب أو الدعدن أو يمكن أن يكون سقفها من مادة نسيجية. 
عناصر الاتصال الحركي: وهي العناصر التي تقوم بالربط والانتقال بين المستويات المختلفة مثل السلالم و المنحدرات و الكباري.

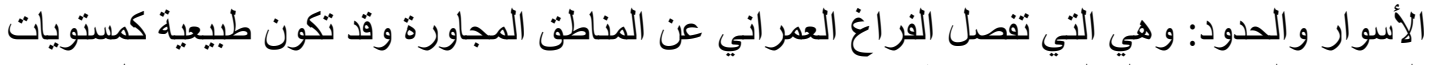

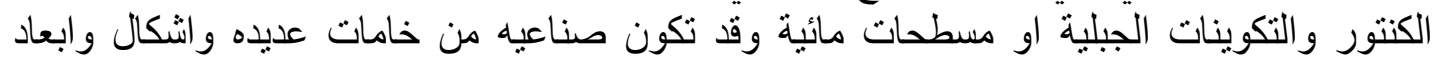
مختلفة.

هواجز الحركة: وتوضع على بعض المسار ات لهنع السيار ات من الدخول او لقصر ها علي حركه المشاة

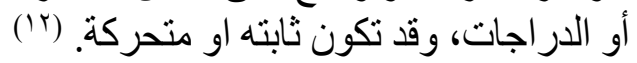

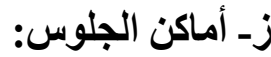

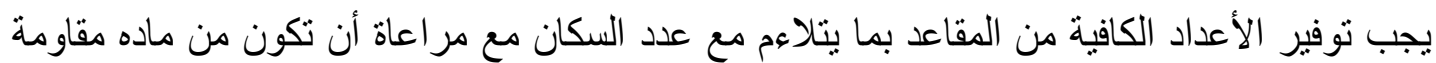

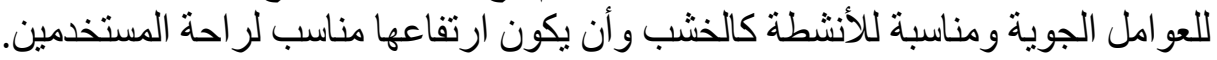

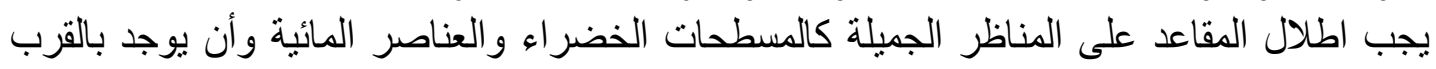

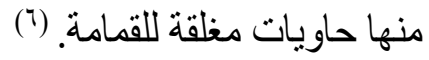

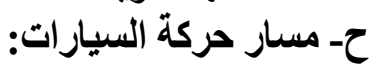

يفضل تصميم شو ارع السيار ات بحيث تكون ذات نهايات مغلقة (Cul-de-sac) مما يسهل فصل الحديقة وحركة الششاة بها عن حركة السيارات. يجب أن يكون مسار المشاة أمن من خلال وجود معابر للمشاة في حالة وجود تقاطع.

r التجمعات السكنية المغلقة: (Exclusive communities - Gated Communists)

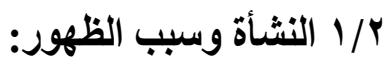

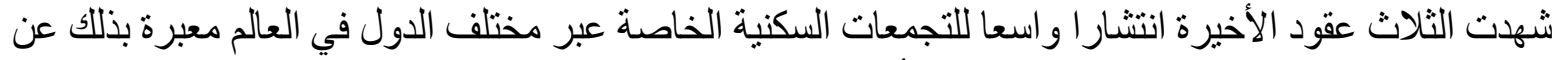

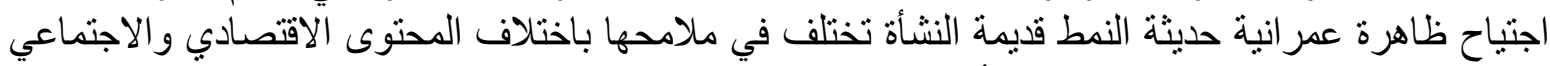

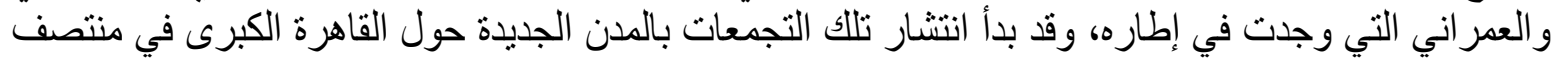

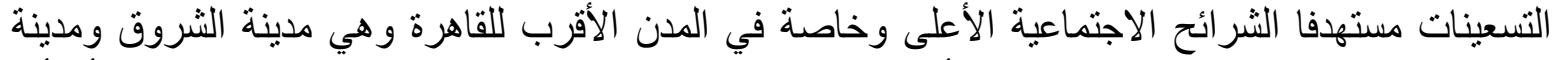

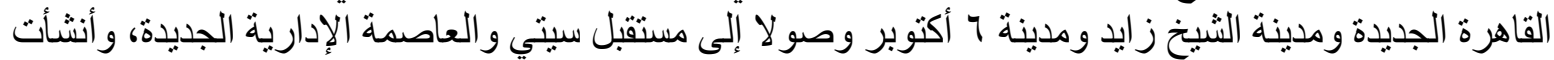
الدولة شبكة جيدة من الطرق السريعة التي تعتبر بمثابة شرايين رئيسية تربط بين تلائك الددن والقاهرة لتيسير

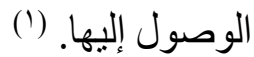

وتتركز أهم أسباب ظهور هذا النهاب النمط من التجمعات السكنية في رغبة قطاع من السكان في التمتع بأسلوب حياة

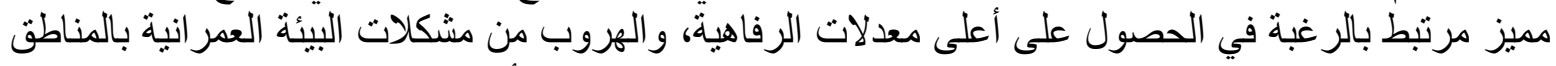

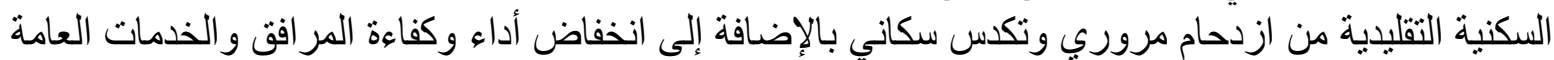

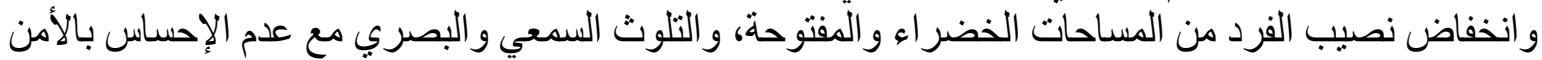

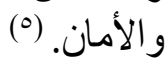

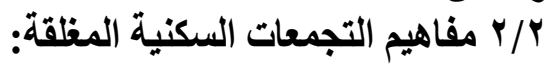

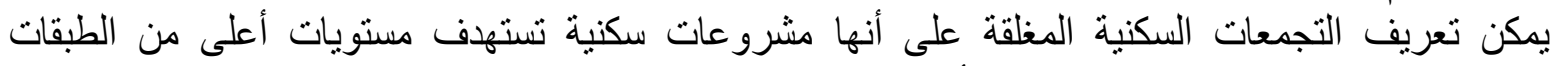

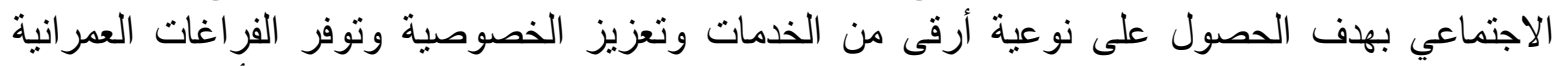

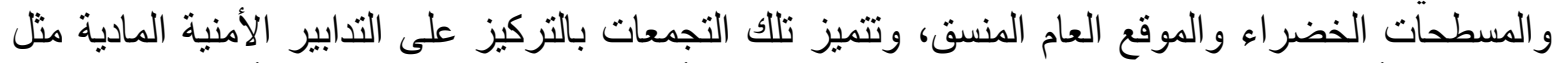

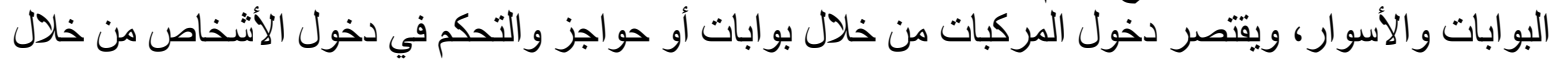

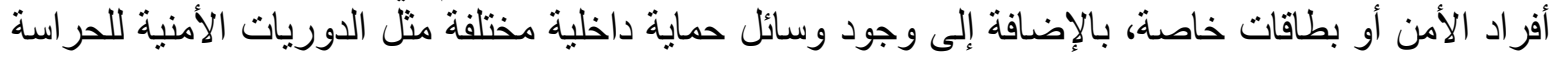

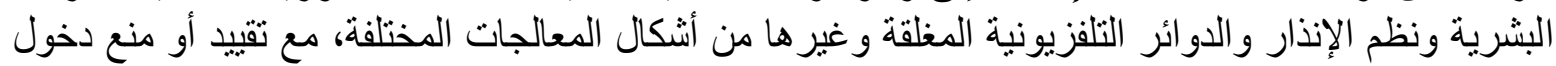

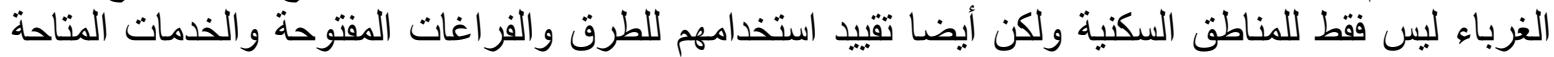

اللسكان. (") 


\section{ك ب/ T/ تصنيف التجمعات السكنية المظقة:}

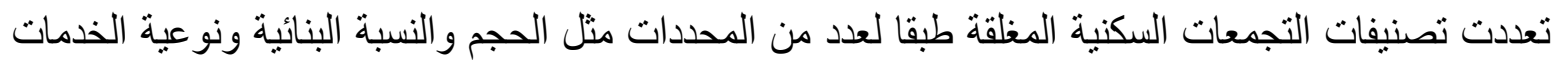

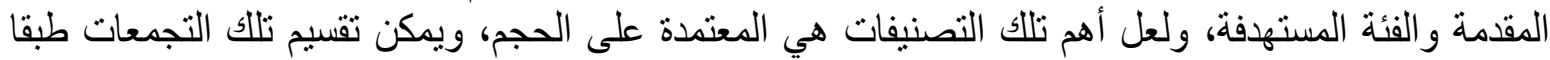

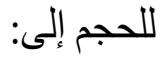

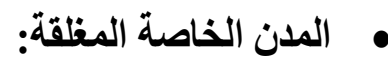

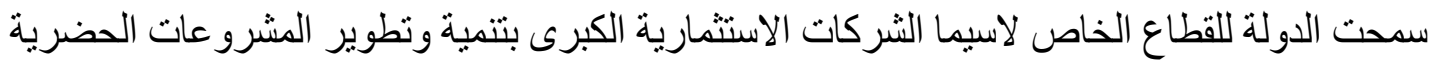

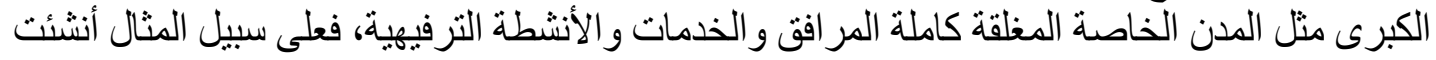

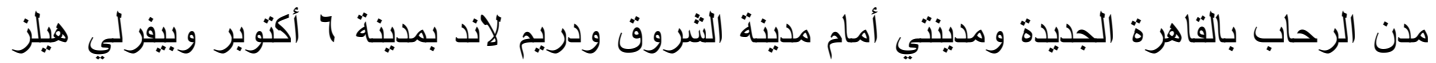
بمدينة الثيخ زايد.

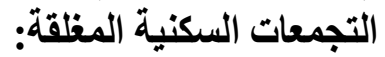
و وهي أقل حجما و أكثر عددا وانتشارا من المدن الخاصة المغلقة، وتختلف فيما بينها أيضا في الحجم وفي

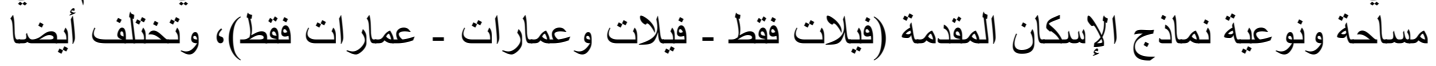

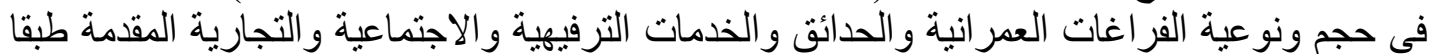

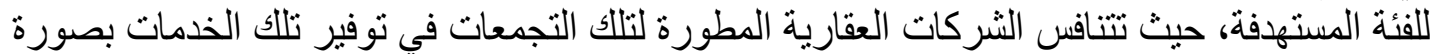

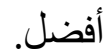

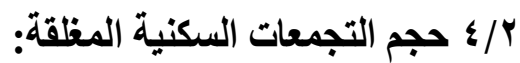
تطورت أعداد التجمعات السكنية المغلقة نتيجة لتز ايد الطلب على هذه النو عية من الإسكان وز ادت نسبة مساحتها

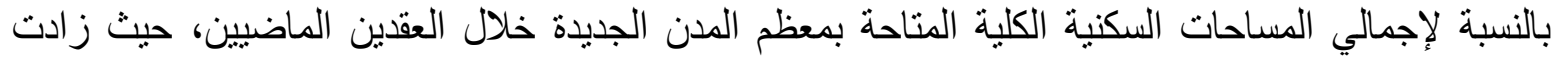

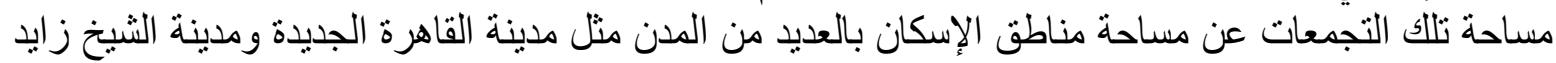

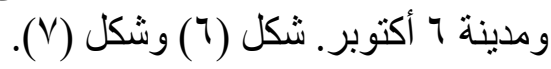

\begin{tabular}{|c|c|c|c|c|}
\hline \multicolumn{4}{|c|}{ التجبعلت البكتية البظقاتة } & \multirow{2}{*}{ سم الملينة } \\
\hline \% للمدبنة & \% لللسكنى & العدل) & العلا & \\
\hline $17 . \mathrm{Y}$ & Tí & $19 \wedge \mathrm{V}$ & $\varepsilon$. & التُزويق \\
\hline 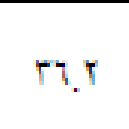 & ov $\mathrm{r}^{2}$ & & 110 & الجديلة \\
\hline$r 9.7$ & 7. & \&ाTा. & $\infty 0$ & ألتبخ ز أبد \\
\hline 19.0 & $0 \wedge \mathrm{Y}$ & $\begin{array}{c}\text { IEOTOY } \\
0\end{array}$ & مؤكِ & 1 أكَكُوبر * \\
\hline
\end{tabular}

شكل (1) أعداد ومسطحات التجمعات السكنية المغلقة بالنسبة لإجمالي مسطحات الإسكان و المدينة (() 


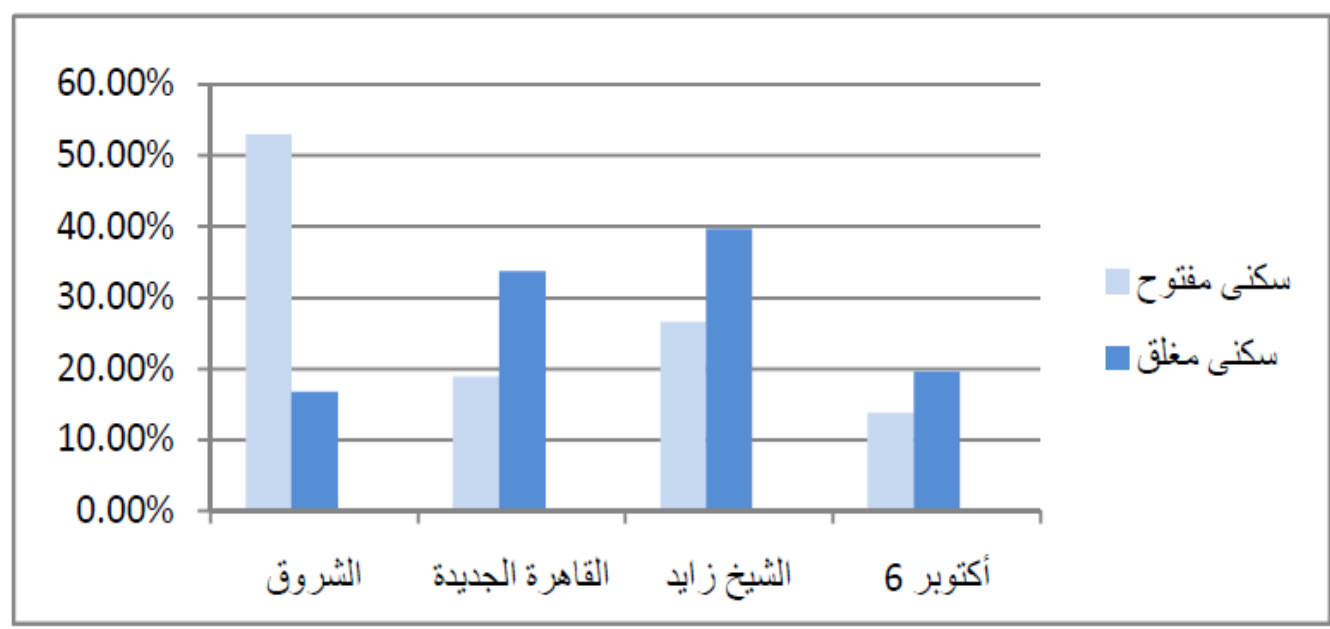

شكل (V) النسب المئوية للمسطحات السكنية المفتوحة و المغلقة بالنسبة لإجمالي مسطح المدينة (')

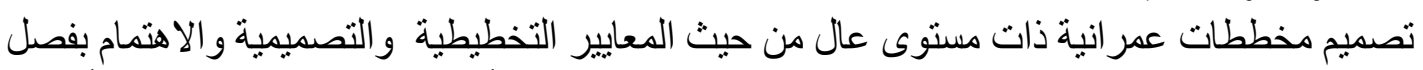

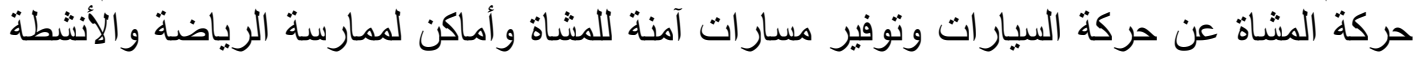

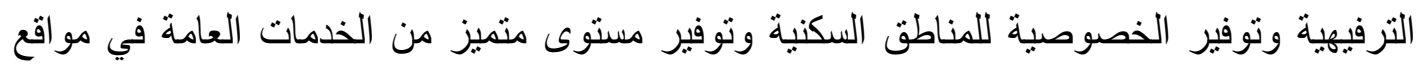

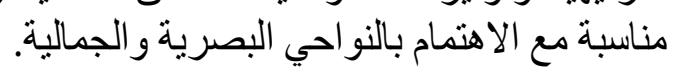

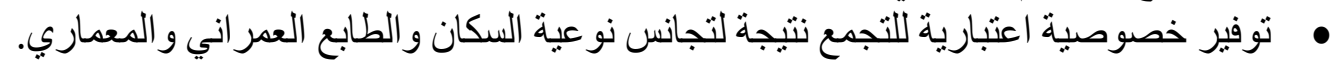

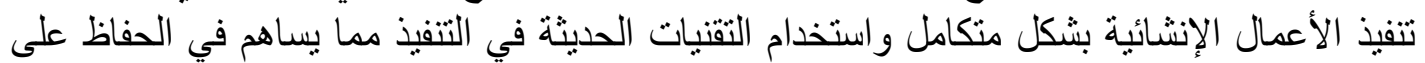

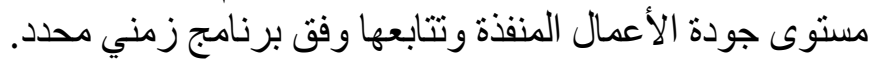

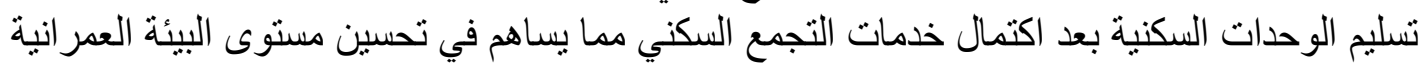

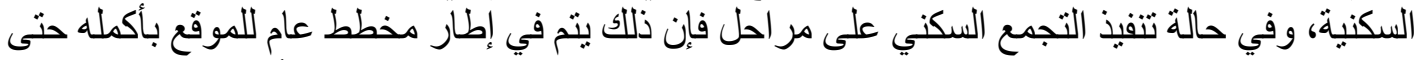

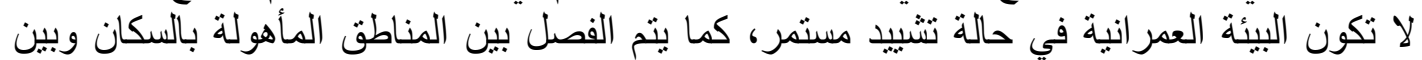
المناطق التي ماز الت تحت الإنشاء.

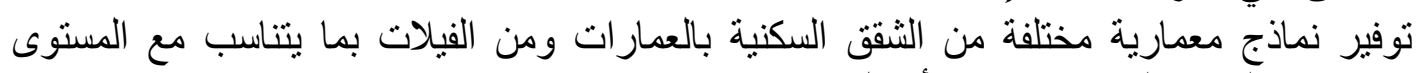

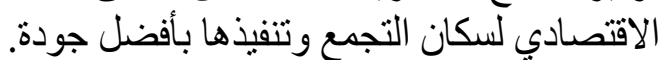

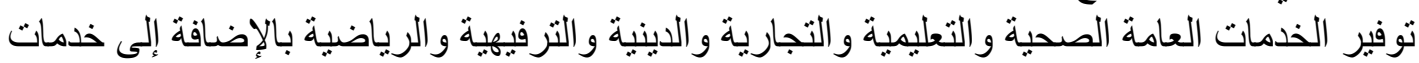

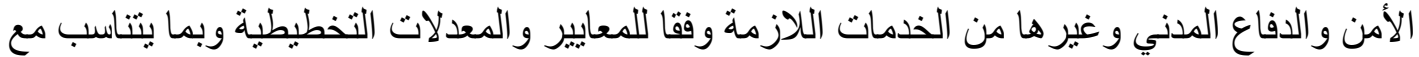
حجم التجمع و الكثافة السكانية بها.

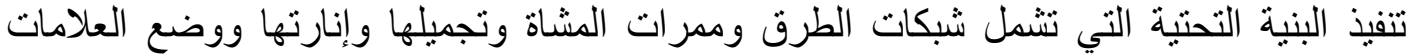

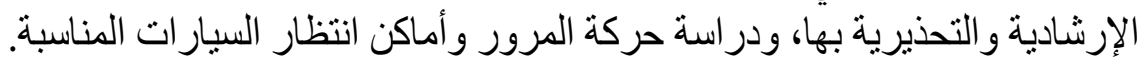

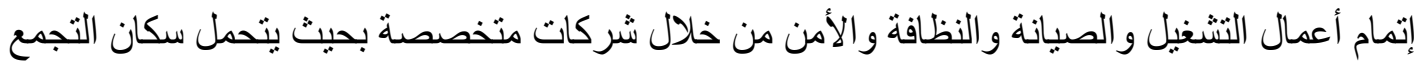

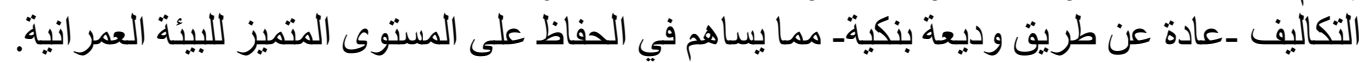
إحكام السيطرة على أعمال البناء مما يقلل من مخالفات البناء(ؤ). 


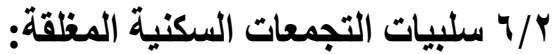

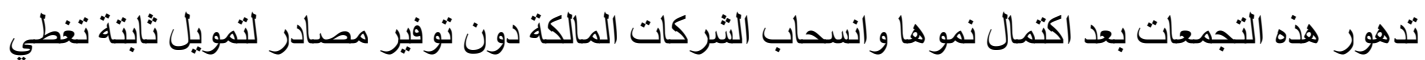

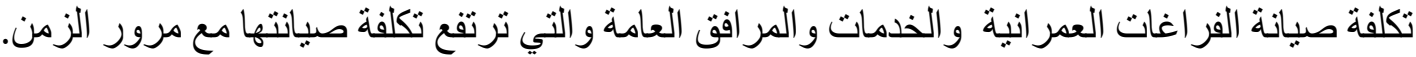

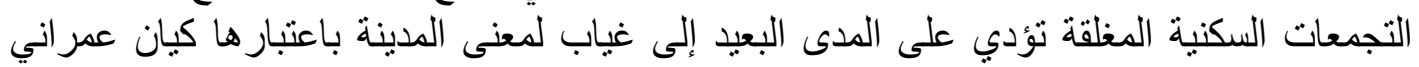

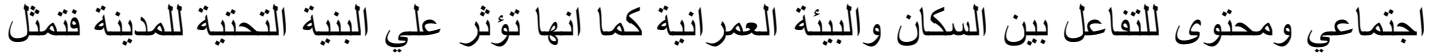

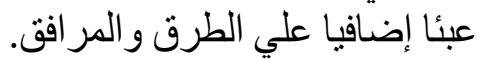

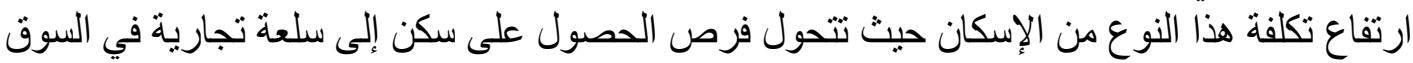

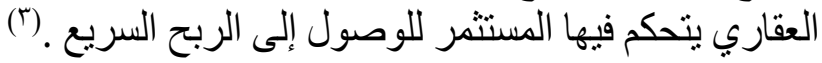

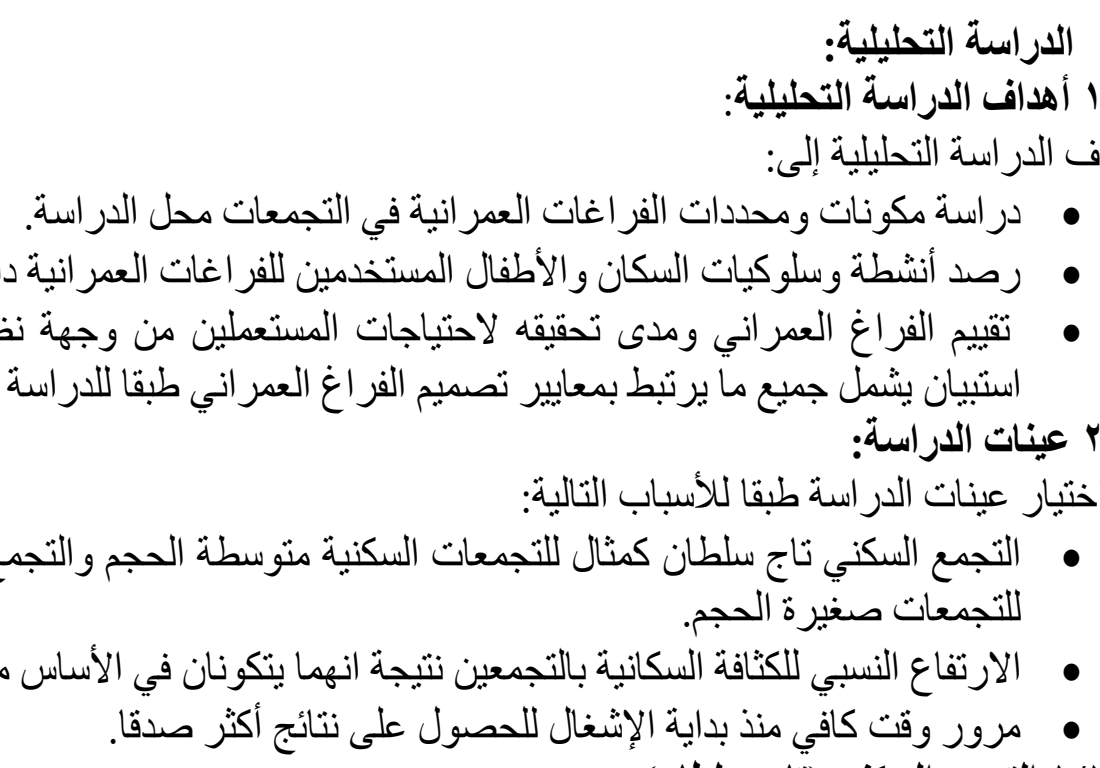

1/ 1/ التجمع السكني (تاج سلطان):

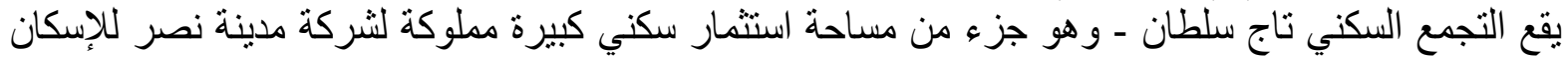

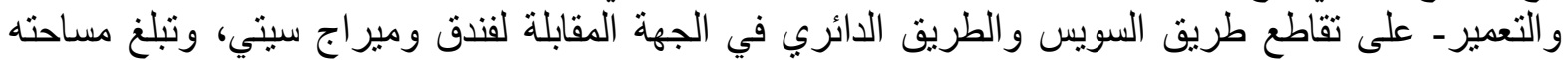

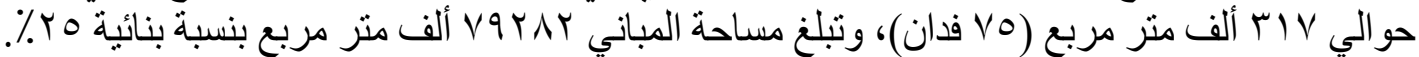

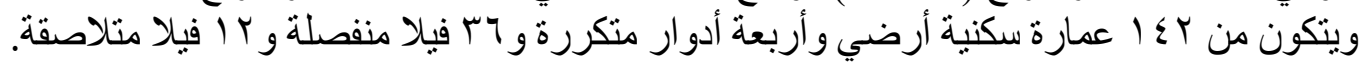

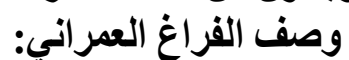

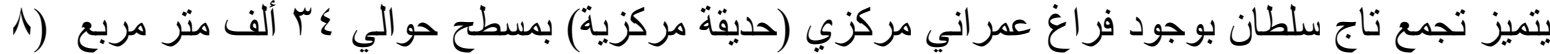

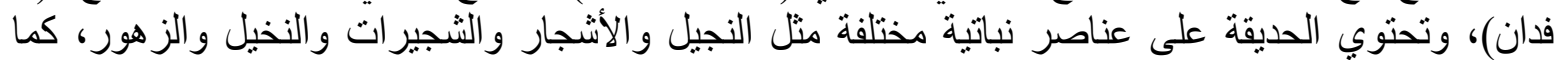

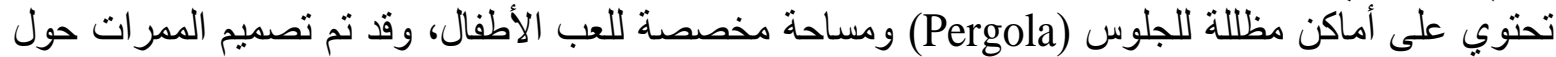

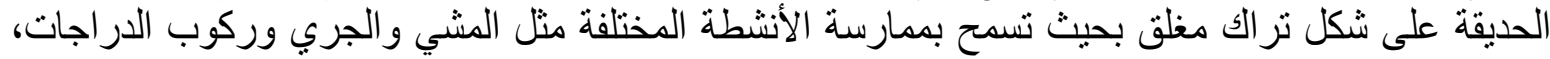

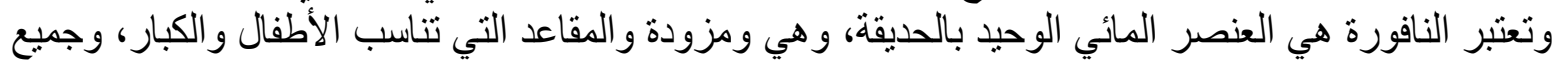

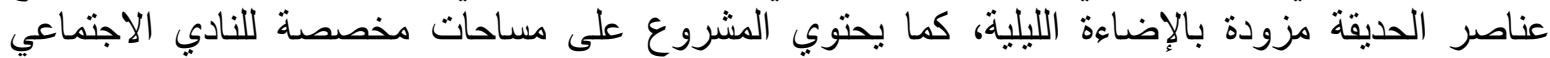
و الملاعب الرياضية والمسجد و التي ماز الت جميعها تحت الإنشاء. 
تحليل الفراغات العمرانية داخل التجمع السكنى (تاج سلطان)

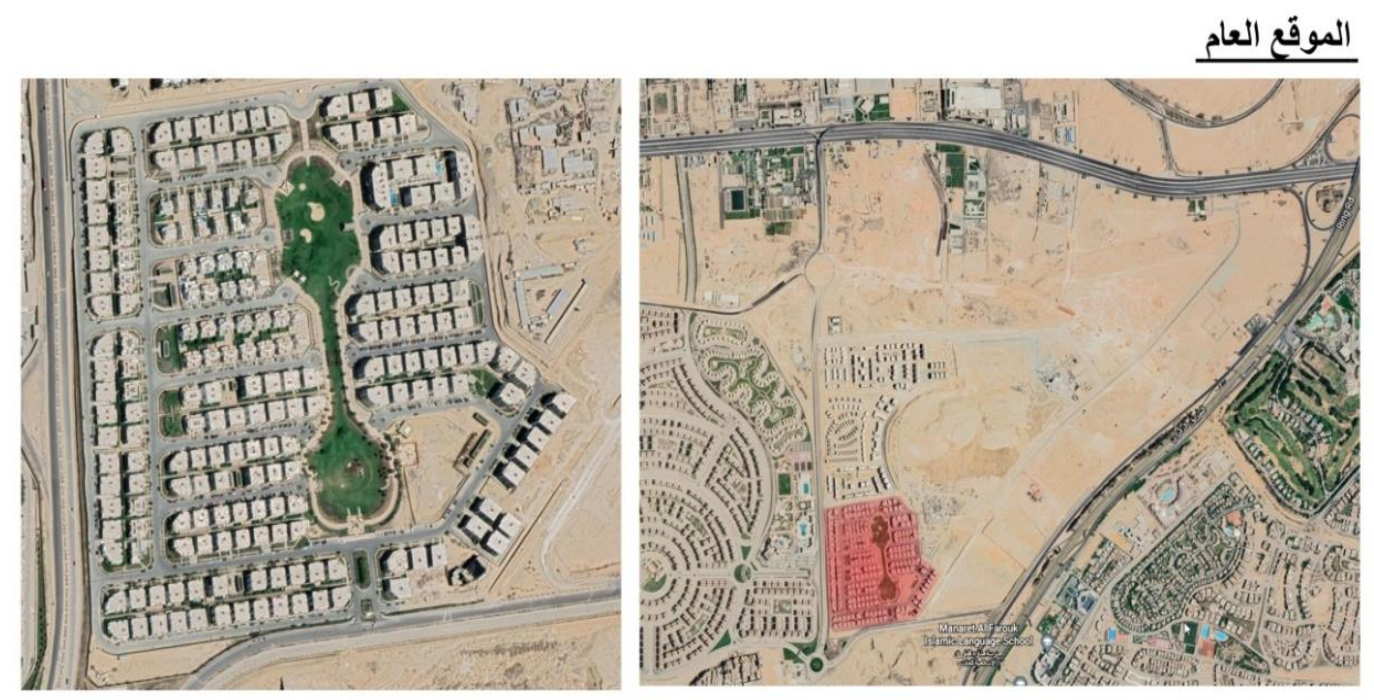

شكل (^) يوضح الموقع العام للتجمع السكنى تاج سلطان المصدر Google Earth

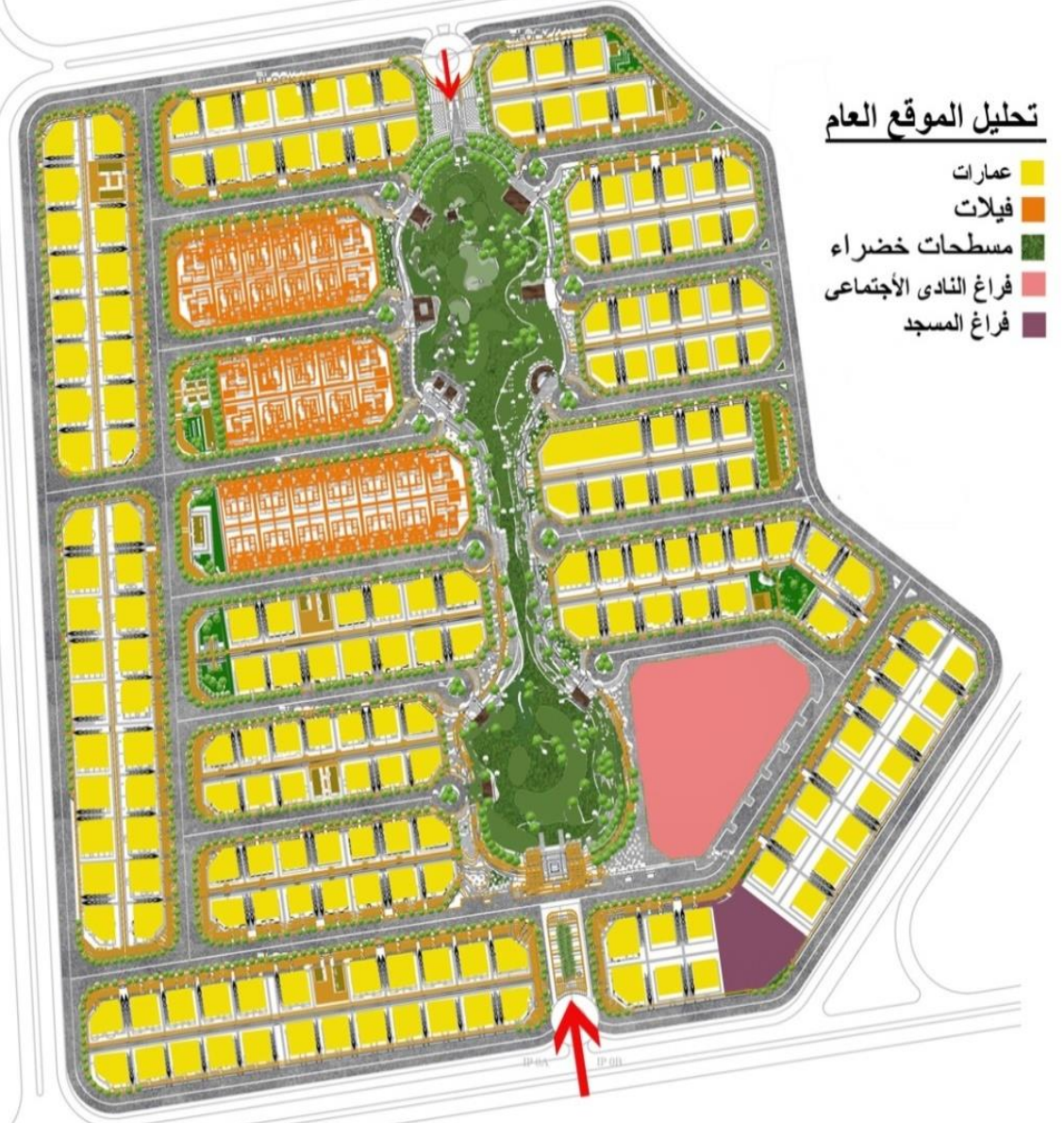

شكل (9) يوضح الموقع العام للتجمع السكنى تاج سلطان المصدر الباحثّن 


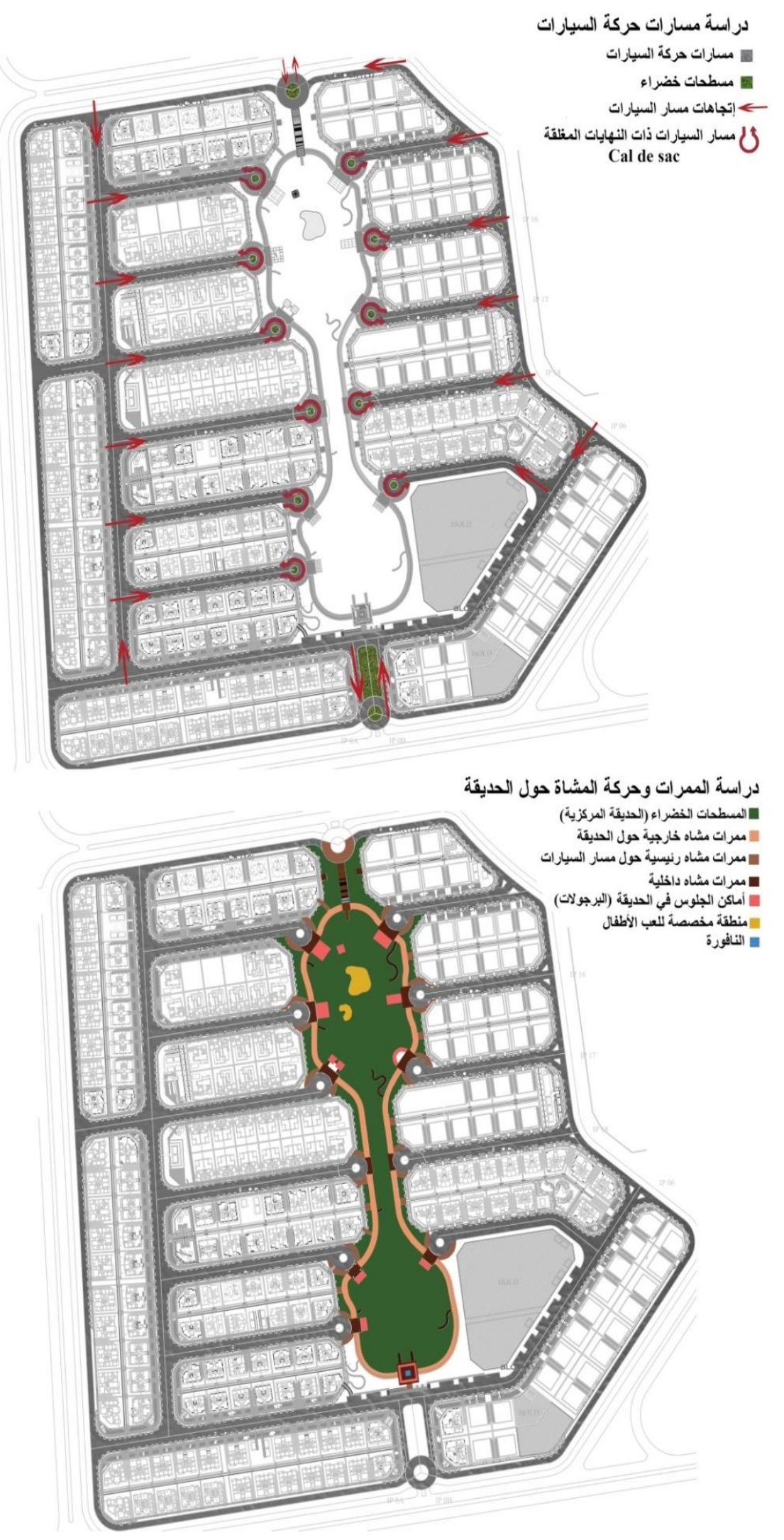

شكل ( • 1) دراسة مسارات حركة السيارات و المشاة بالتجمع السكني تاج سلطان المصدر الباحثون 


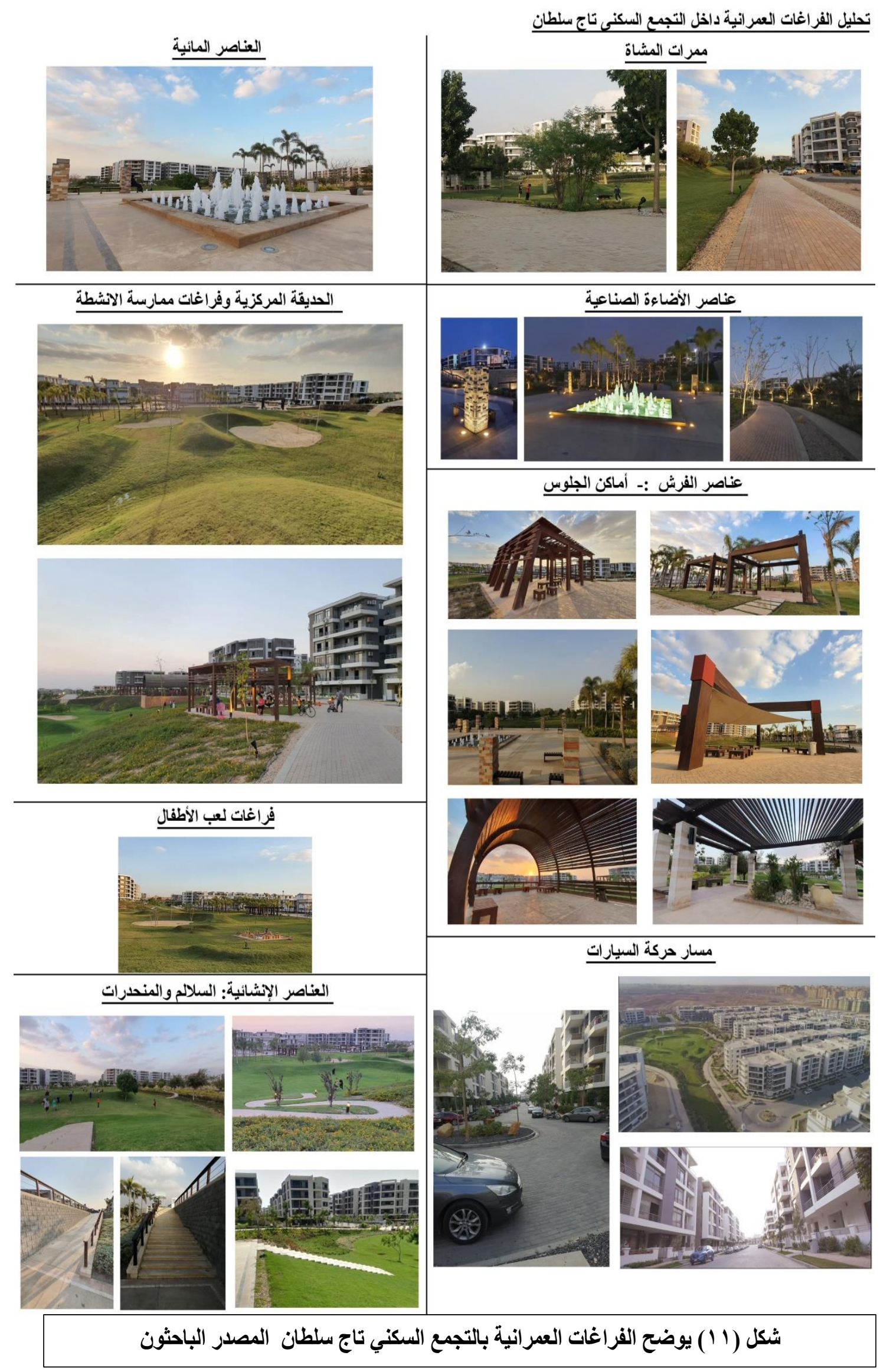




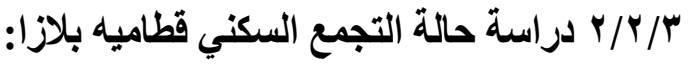

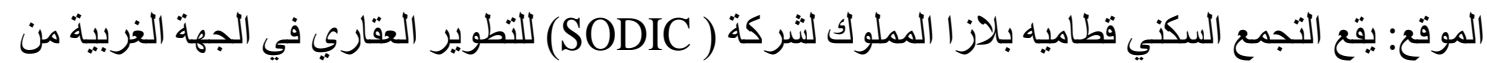

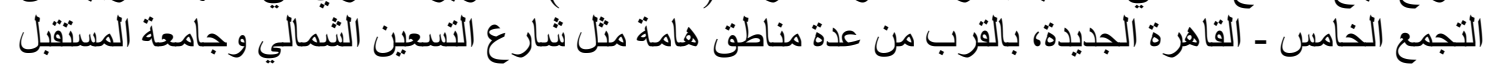

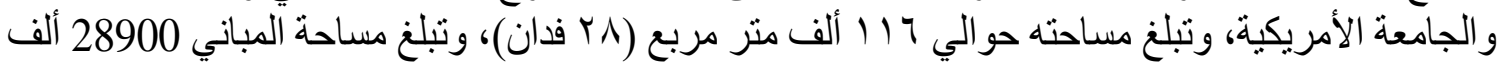
متر مربع بنسبة بنائية 25\%.

ويتكون من 36 عمارة سكنية أرضي وأربعة أدوار متكررة وملحق سطح و5 فيلا منفصلة. وصف الفراغات العمراني:

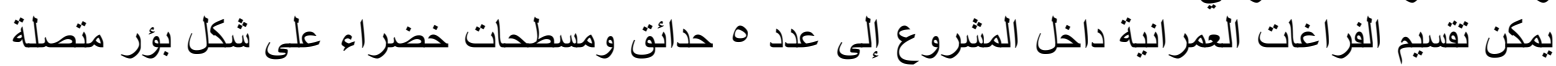

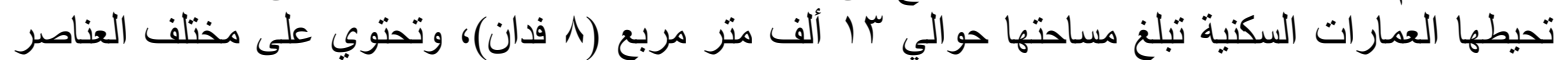

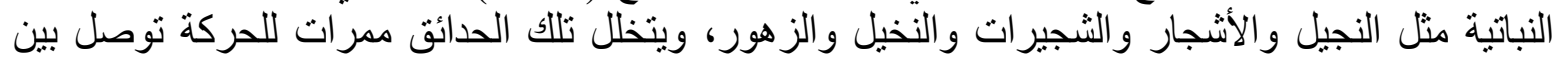

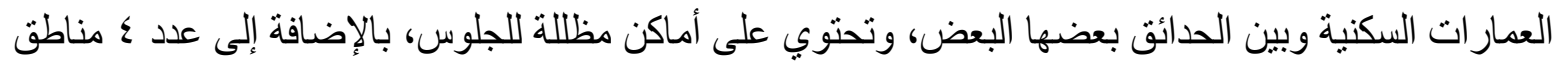

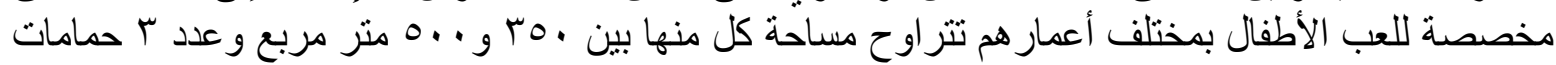

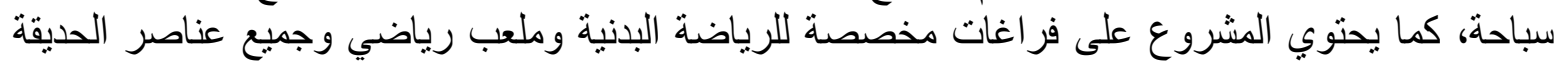

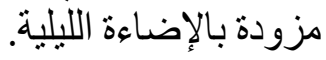

تحليل الفراغات العمرانية داخل التجمع السكنى (قطاميه بلازا)

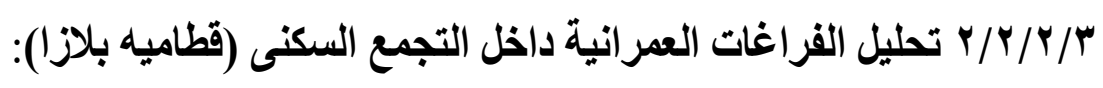

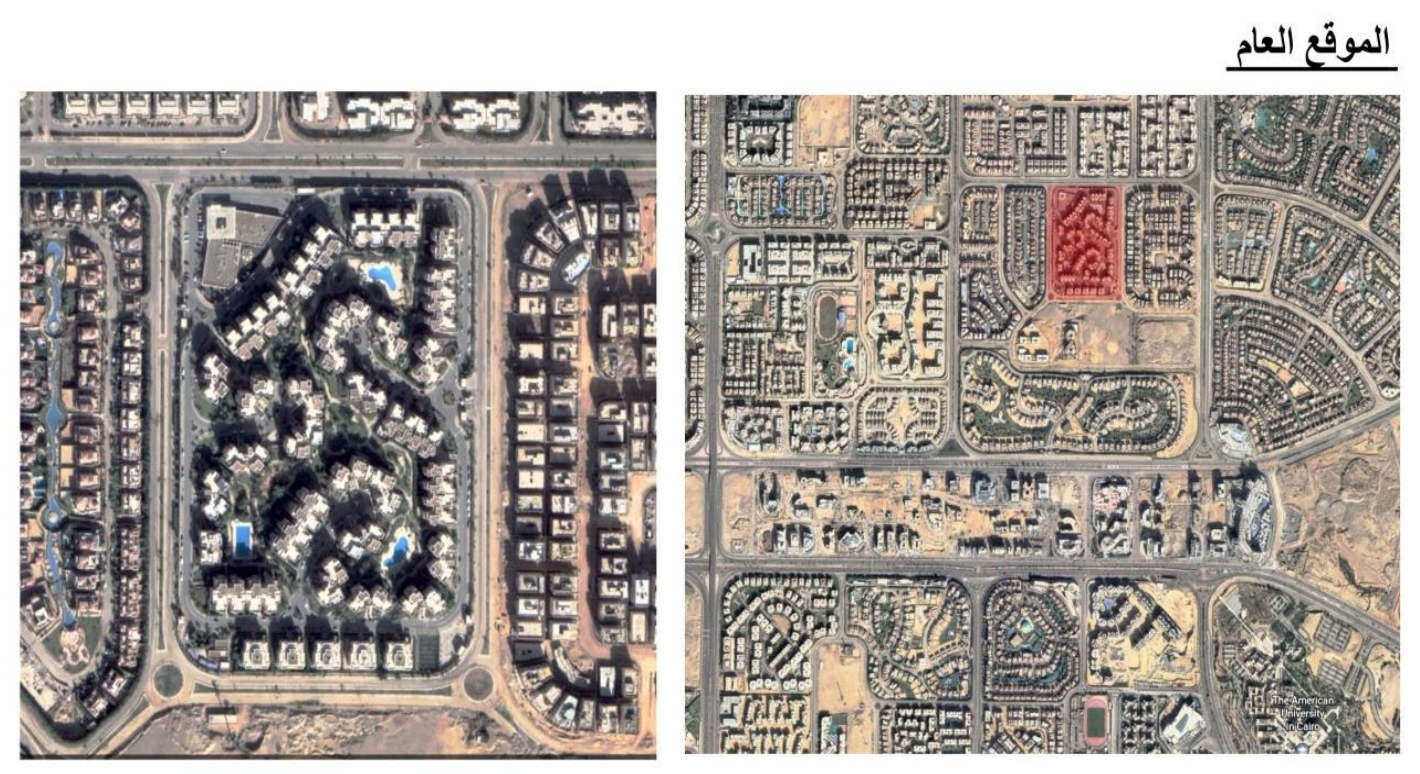

شكل (r ا ) يوضح الموقع العام للتجمع السكنى قطاميه بلازا المصد Google Earth 


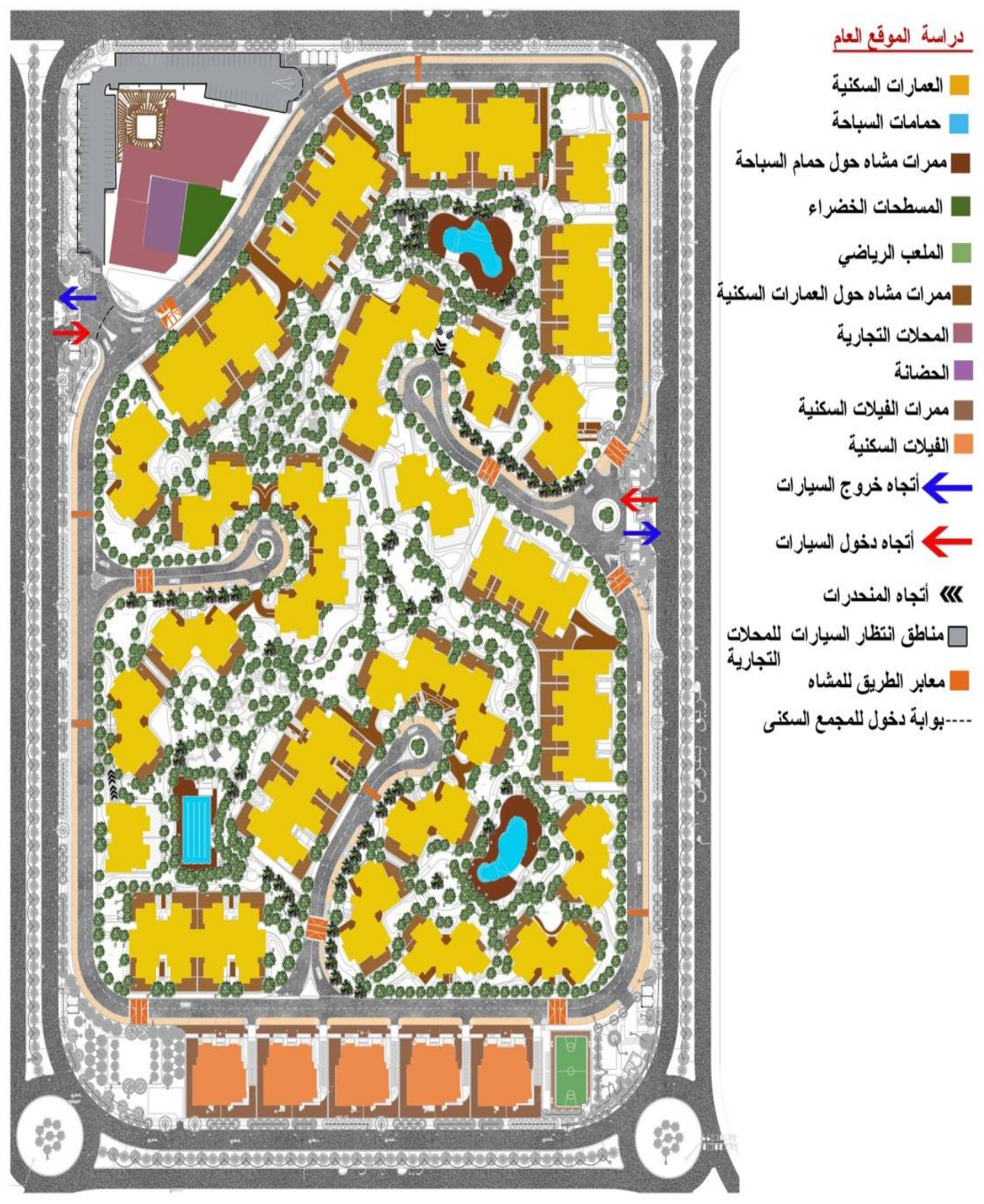

شكل (ب ا ) يوضح الموقع العام للتجمع السكنى قطاميه بلازا المصدر الباحثون 


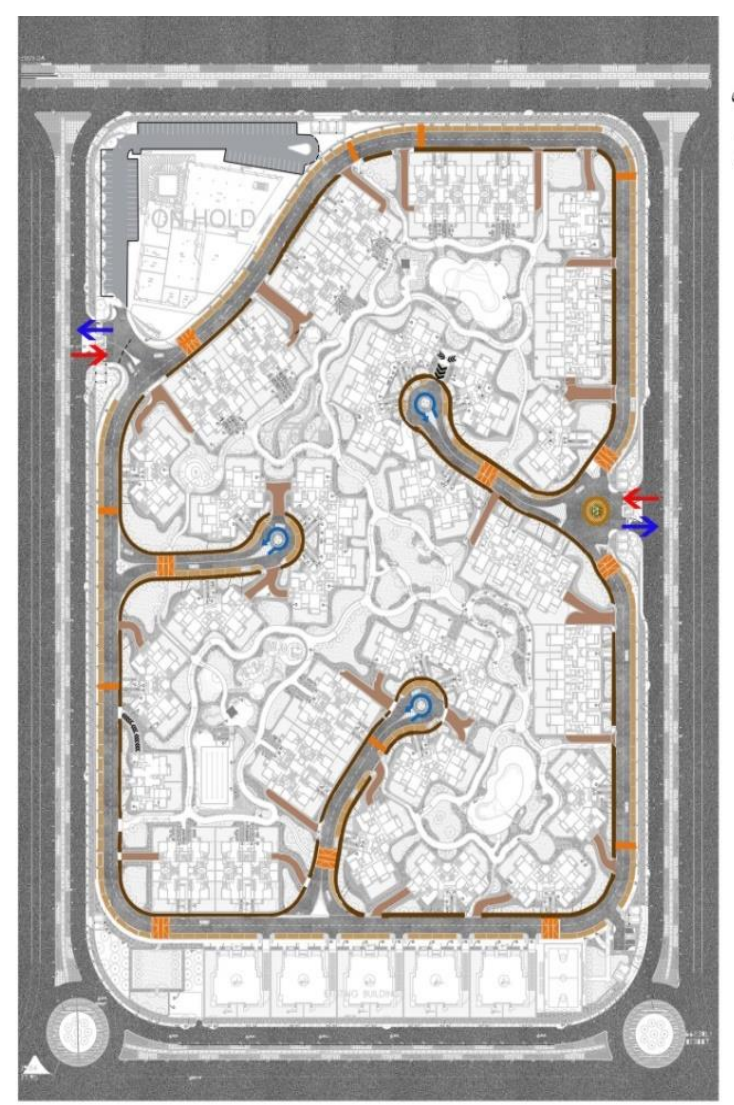

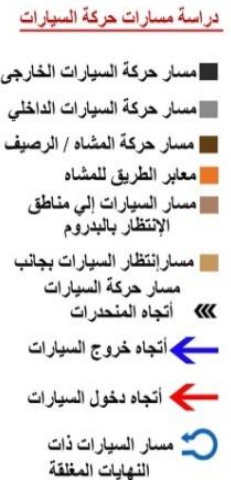

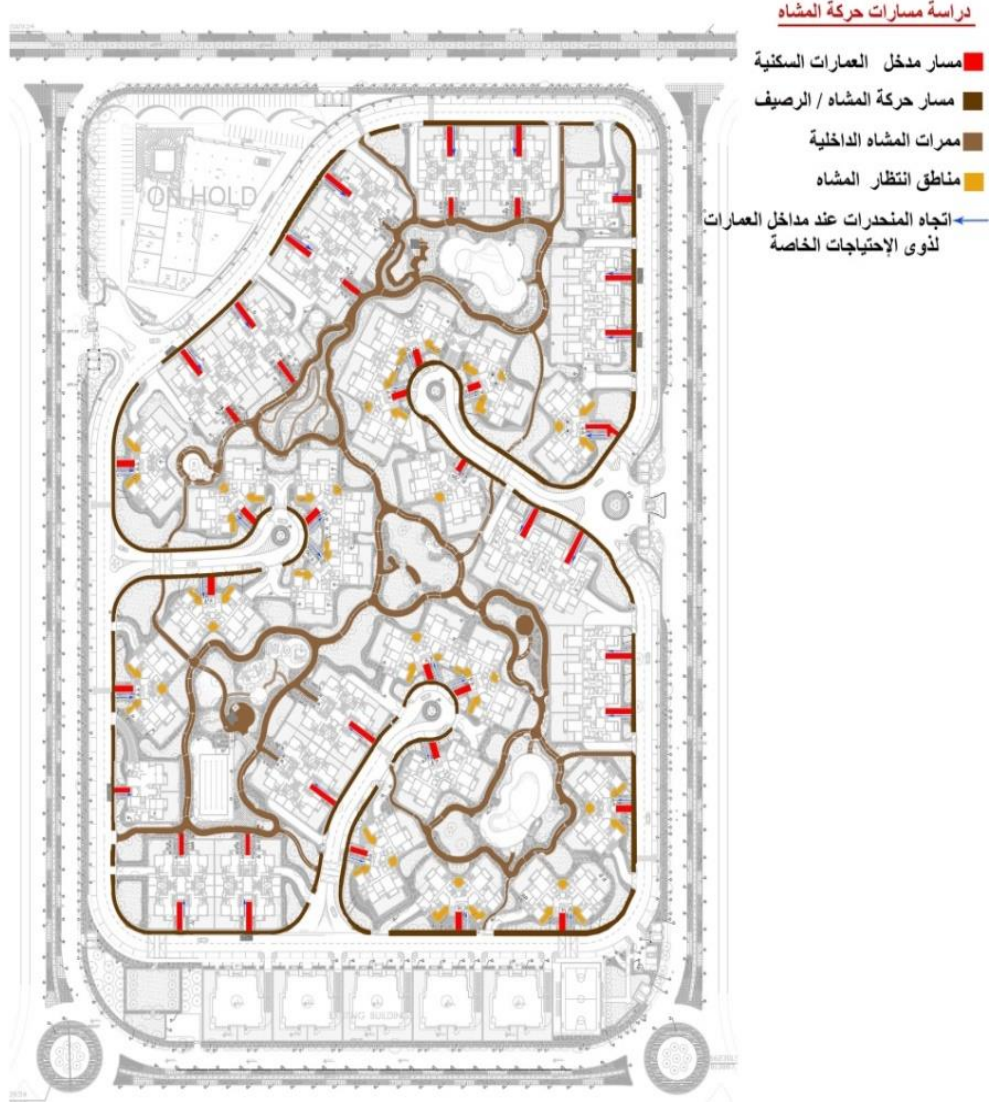

شكل (؛ () دراسة مسارات حركة السيارات و المشاة بالتجمع السكني قطاميه بلازا المصدر الباحثون 

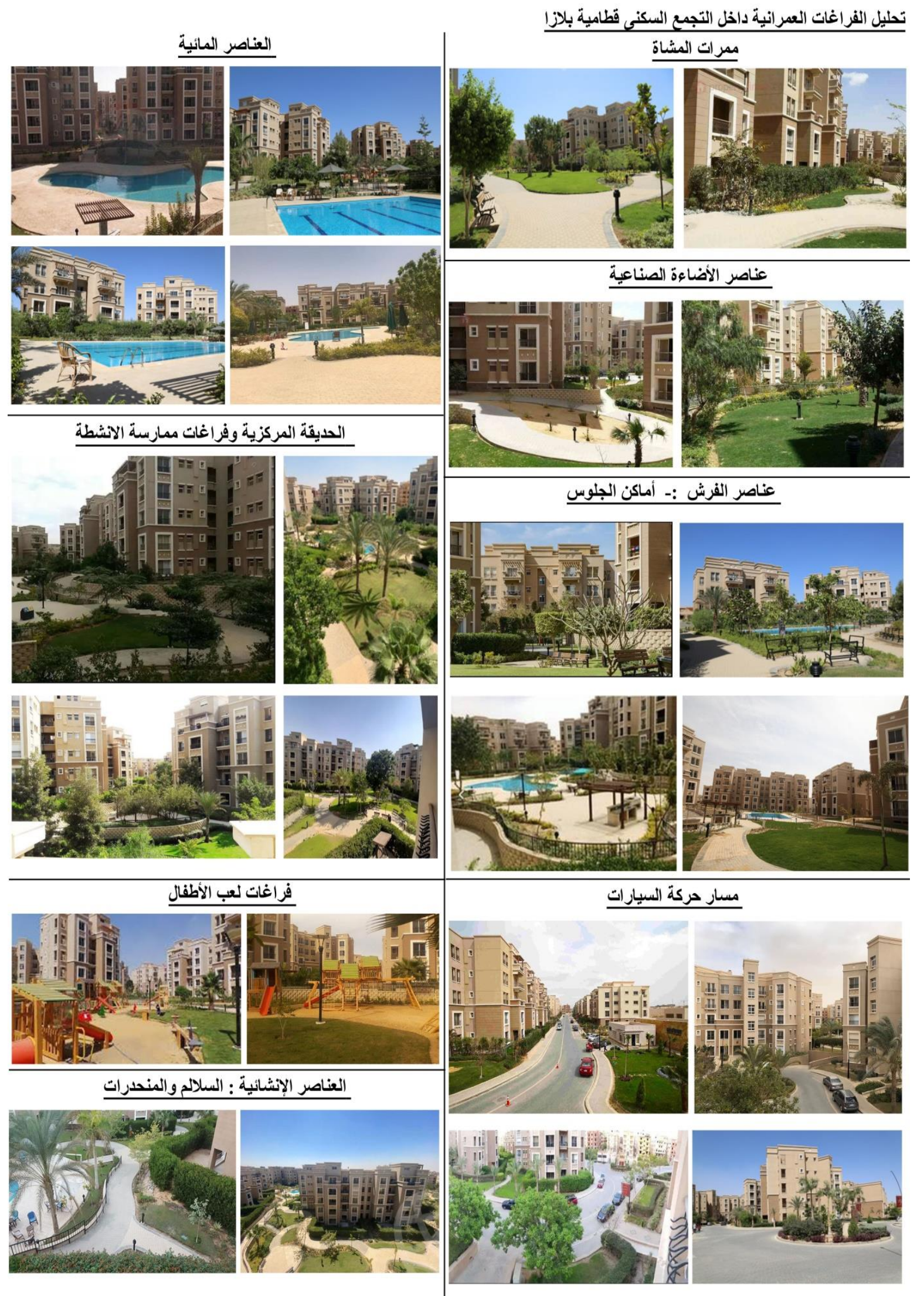

شكل (0 1 ) يوضح الفراغات العمرانية بالتجمع السكني قطاميه بلازا المصدر الباحثون 


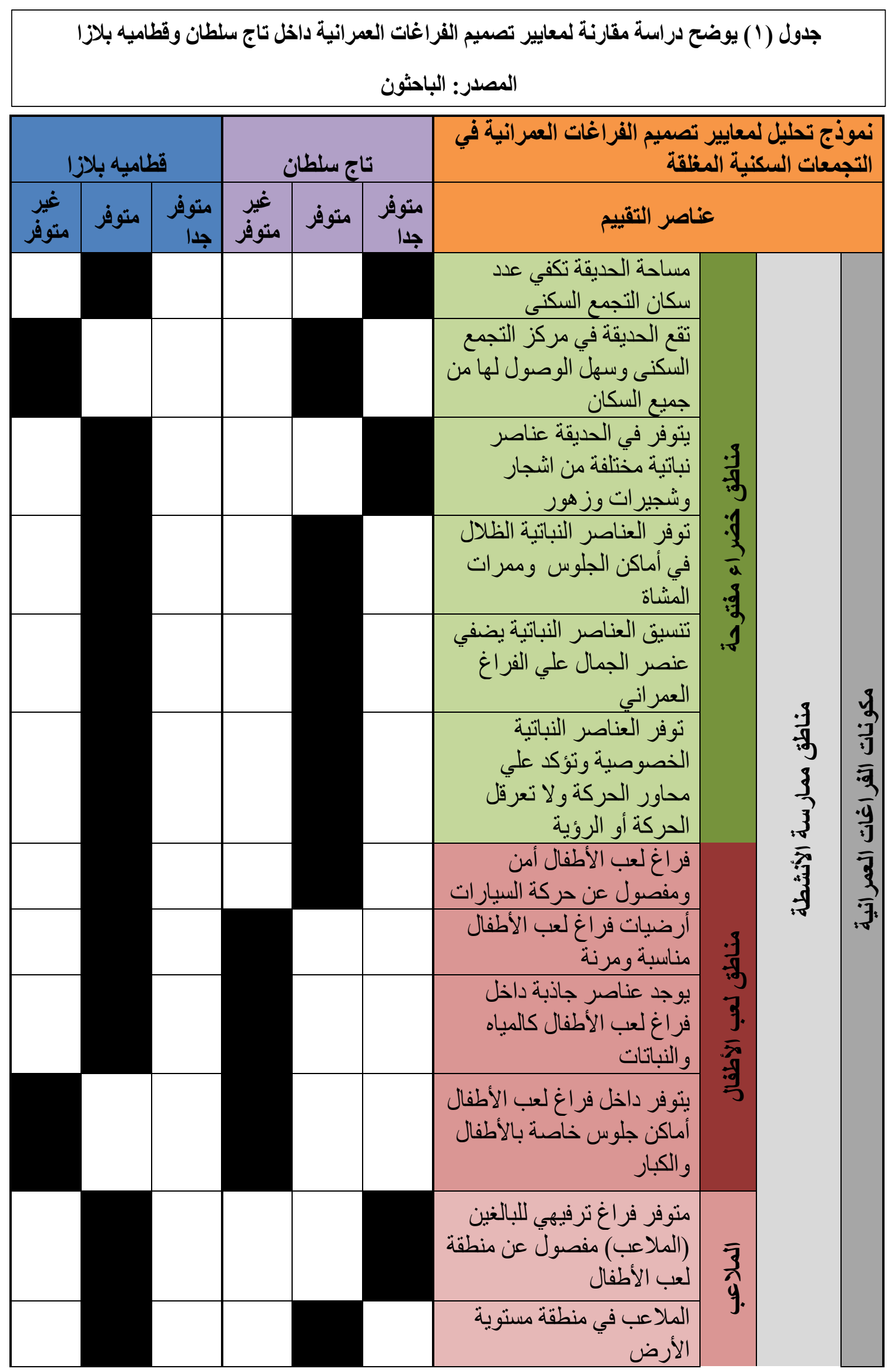




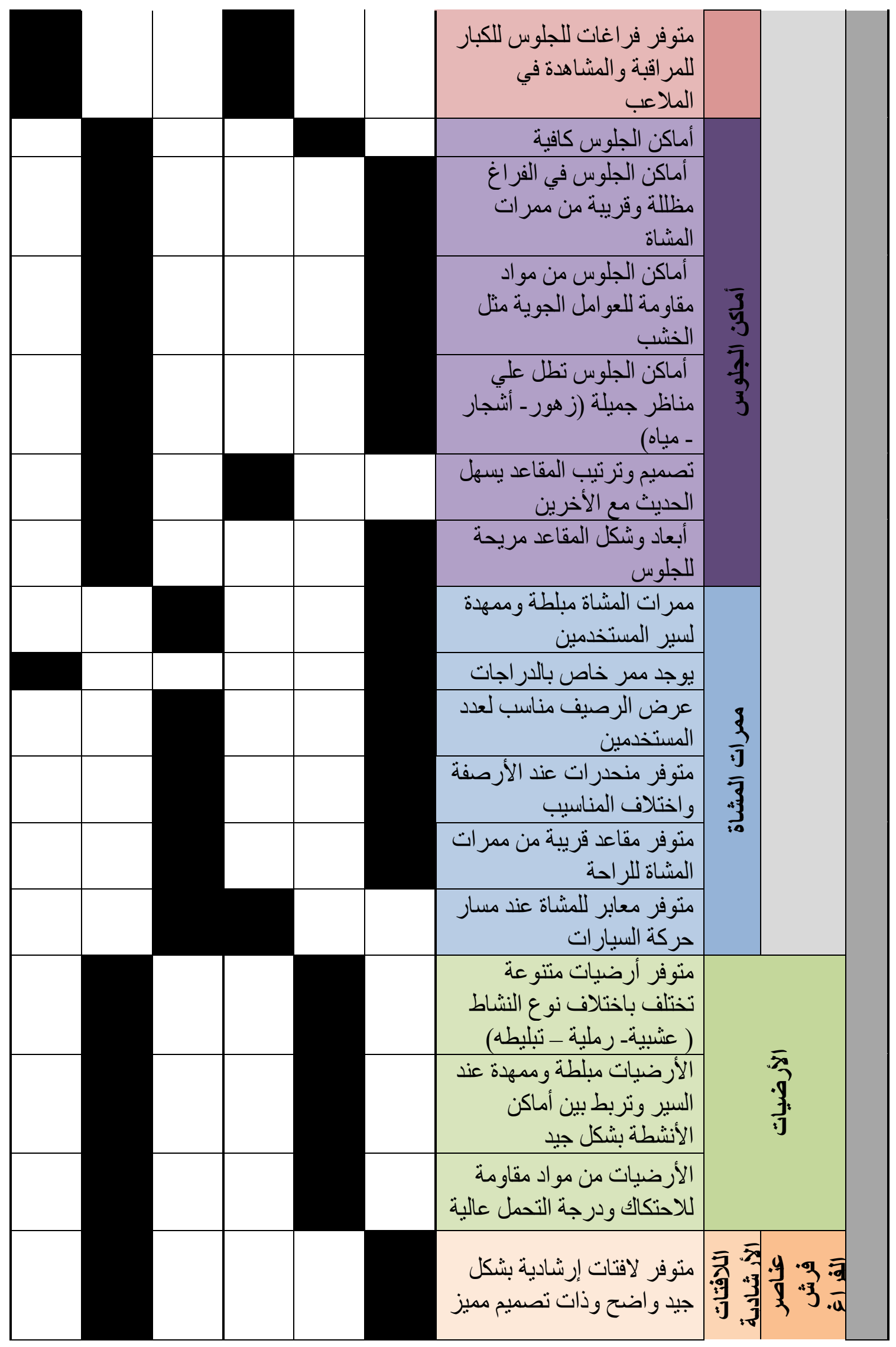




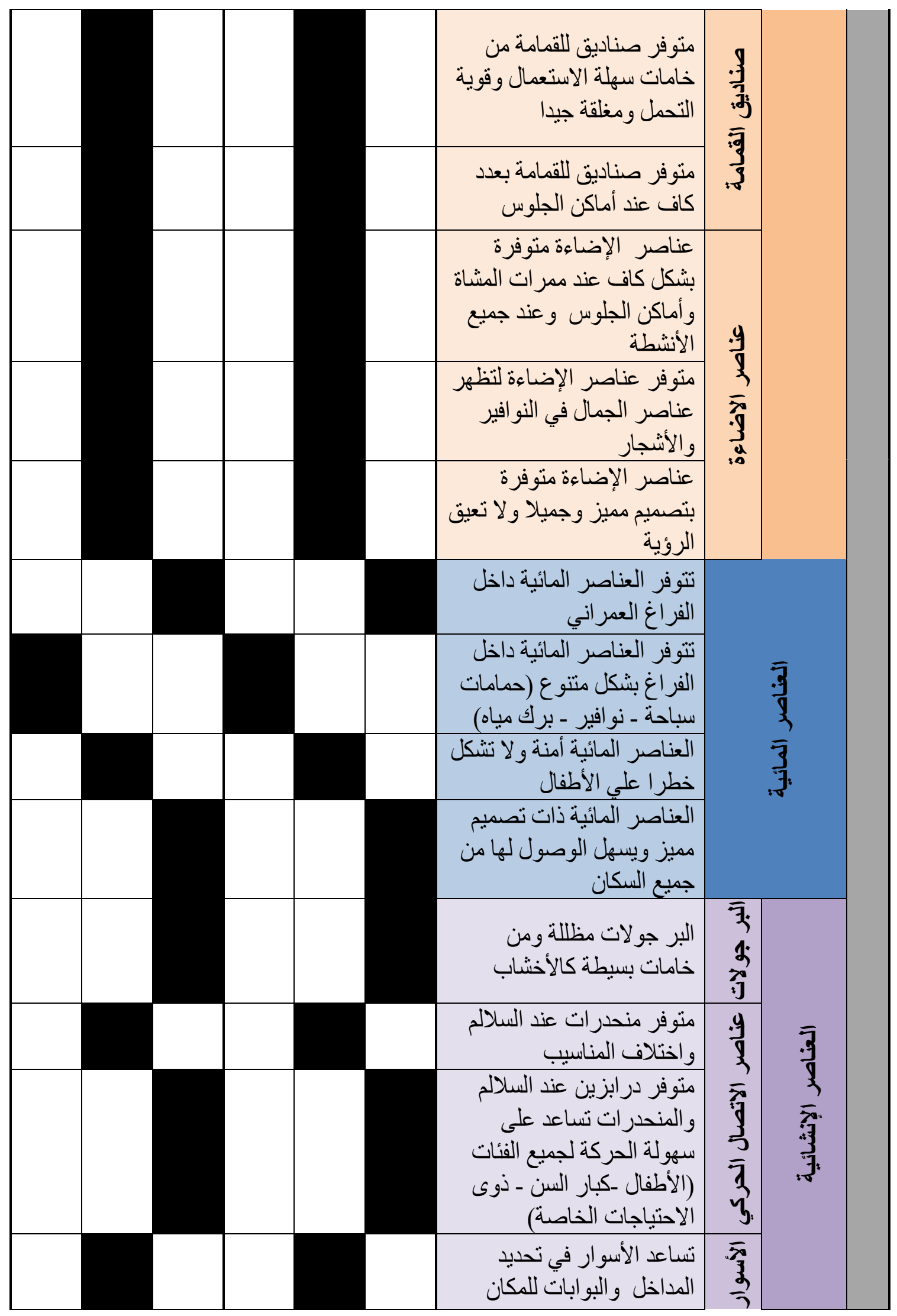



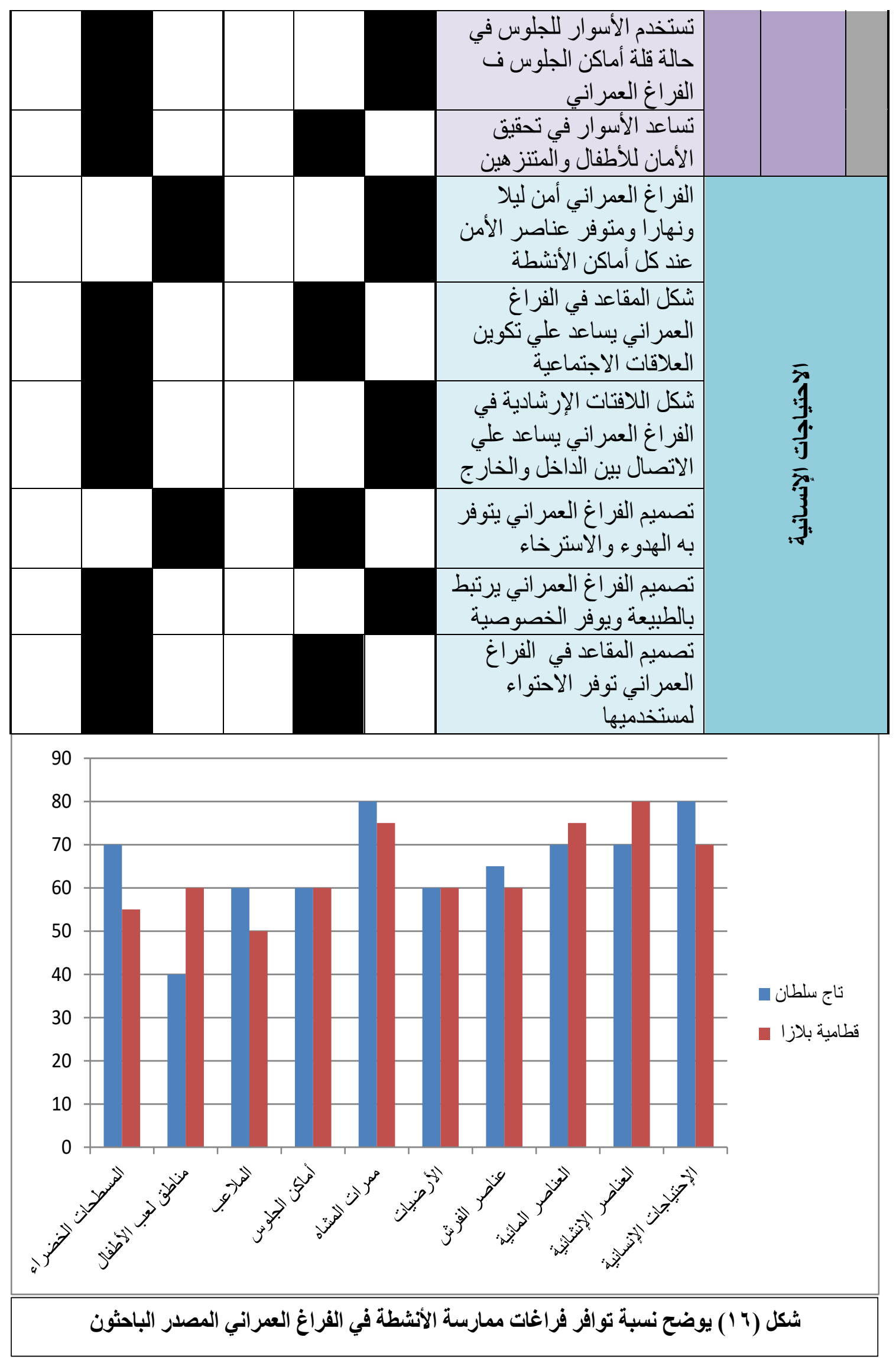


\section{r/r/ نتائج التحليل: بتحليل نتائج الاستبيان السابق نجد ما يلي:}

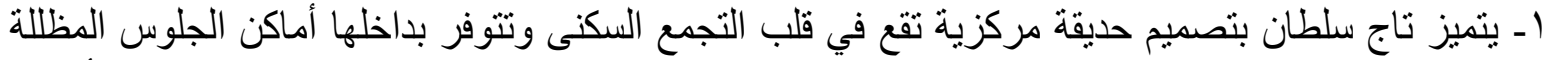

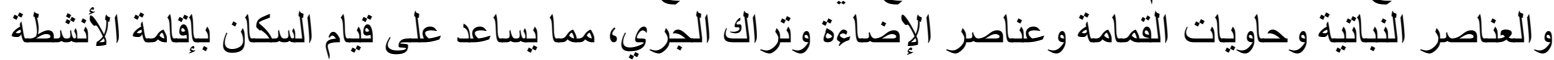

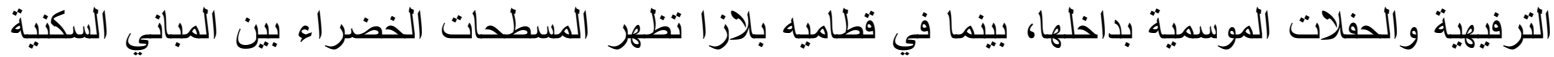
ويرجع ذللك إلي صغر مساحته مقارنة بمساحة تاج سلطان .

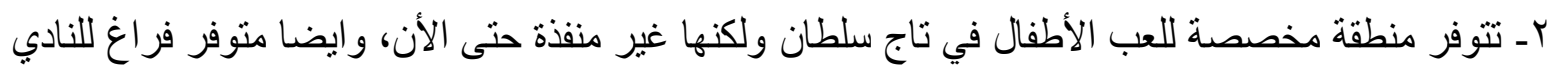

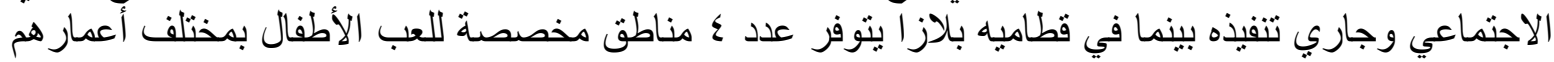

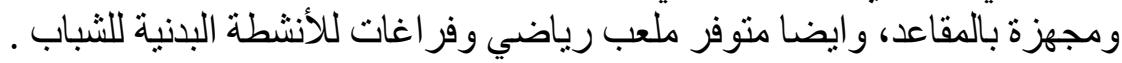

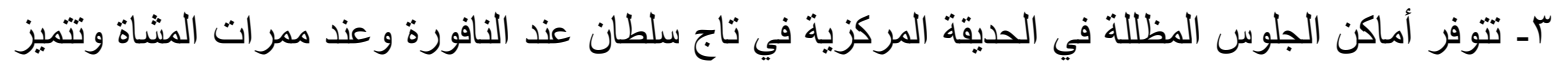

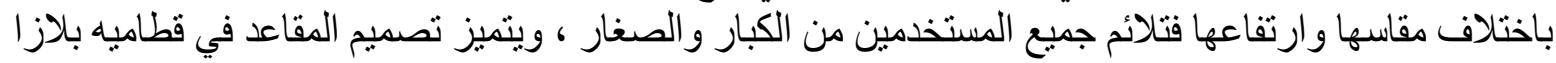
بعنصر الاحتو اء مما بيساعد على التآلف الاجتماعي. ـ ـ عدد أماكن الجلوس في تاج سلطان وقطاميه بلازا حتى الأن تكفي عدد السكان، ولكن يتوقع مع اكتمال عدد السكان ستصبح غير كافية.

هـ يتميز تصميم الممر ات في تاج سلطان وقطاميه بلاز ا بالتصميم العضوي فنلاحظ عدم طول الممرات وفصلها

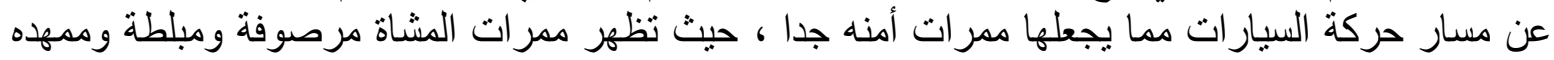

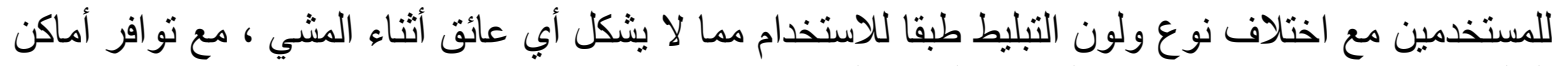
الجلوس وعناصر الإضاءة بجوار الممر ات لراحة المستخدمين.

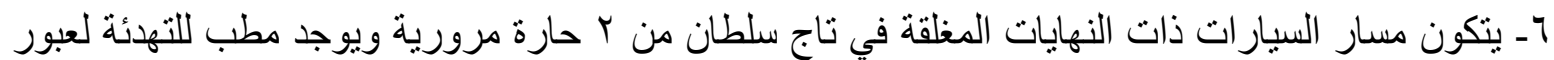

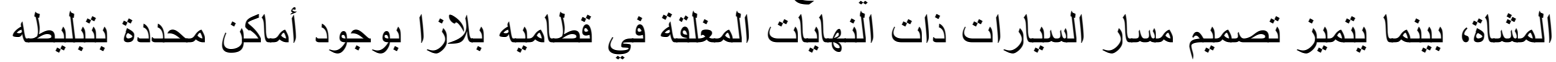

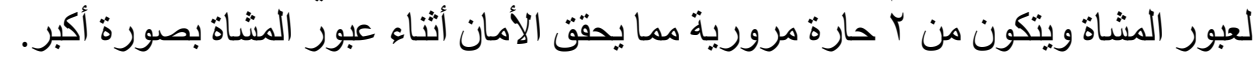

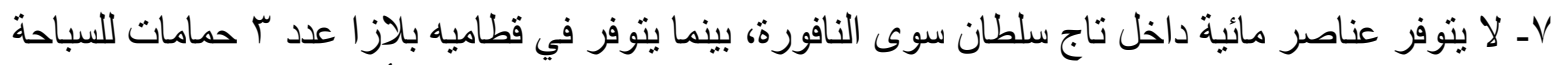

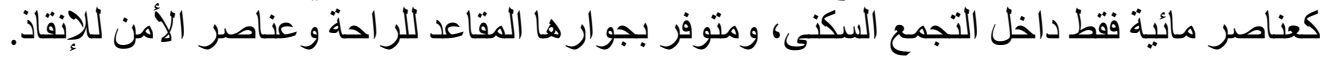

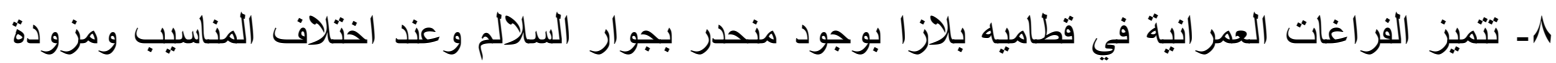
بدرابزين عند الفراغ العمراني ويظهر ذللك ايضا في تاج سلطان عند اختلاف المناسيب في الحديقة المركزية

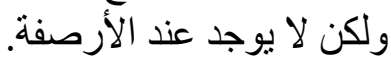

9ـ تحقق الفراغات العمر انية في تاج سلطان و قطاميه بلازا الاحتياجات الإنسانية حيث يتسم تصميم الفر اغات

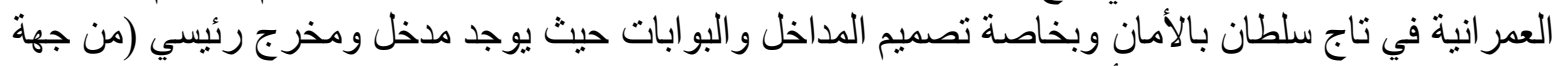

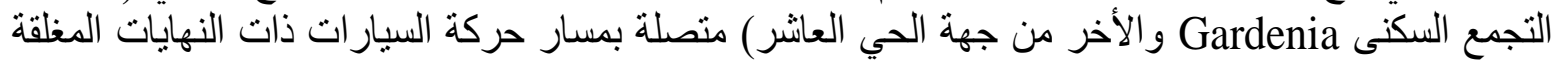

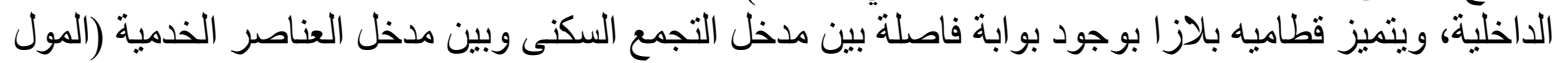

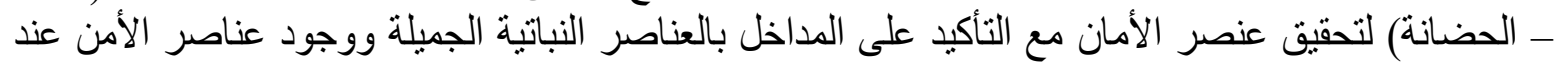
البوابات مما يشكل عنصر الأمان في التجمعات السكنية.

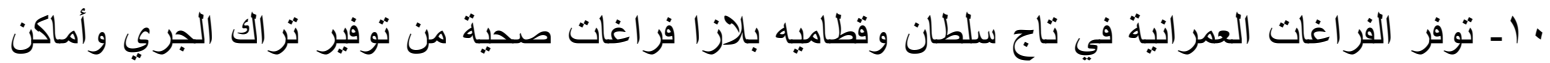

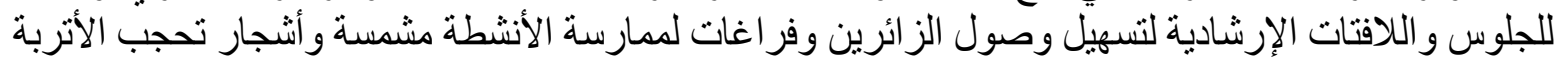

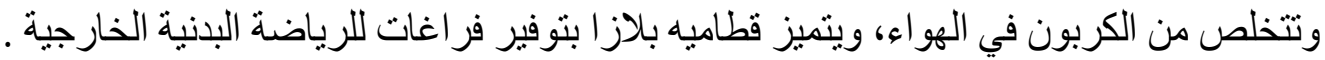


• تناول البحث در اسة مفاهيم و مكونات الفر اغ العمر اني و المعايير التصميمية لمكونات الفراغ العمر اني اللازم

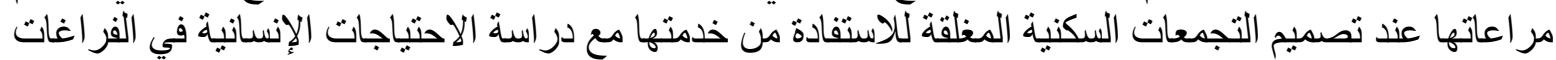

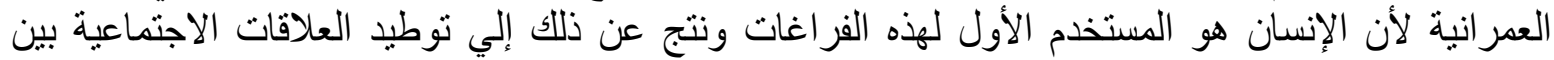

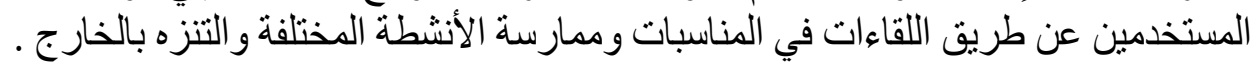
• إن تقييم الفر اغات من خلال المستخدمين أحد أهم عناصر إعادة صباغة شكل ووظيفة الفراغات التي يسكنون فيها و التي تتشكل مكوناتها حسب أعمار هم و اساليب حياتهم و منطلباتهم .

• إن الربط بين الفراغات الداخلية والفراغات الخارجية بيساعد في نجاح الفراغات الخارجية في أداء وظيفتها

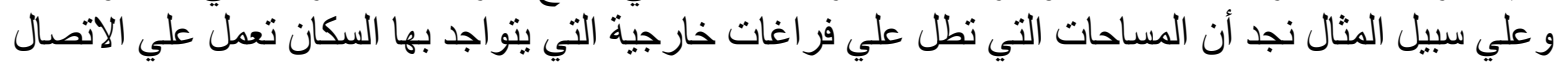

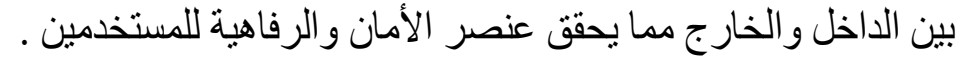

• إن التجمعات السكنية المغلقة ظاهرة حديثة النمط قديمة النشأة، حيث انها تجمعات سكنية مغلقة بأسوارها

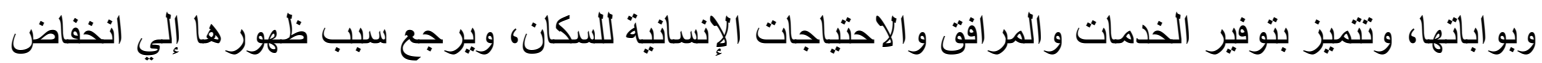

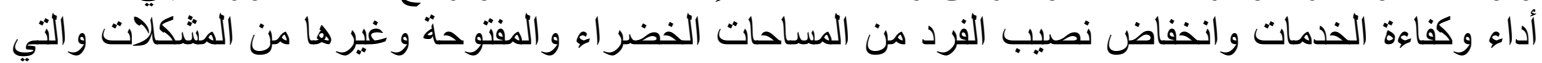
اعتبرت بمثابة قوي طاردة دفعت بعض السكان للخروج من مجتمعاتهم المحلية إلي تلك التجمعات بحثنا عن حياة

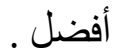

\section{المراجع: (1)}

ا ـ أبو زيد، مها عبدالستار عبد الرشيد. إطار ومنهج لتقييم التجمعات السكنية المغلقة، رسالة دكتور اه، كلية

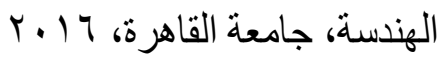

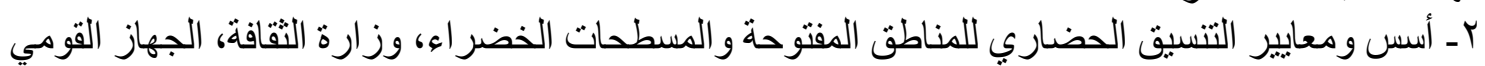

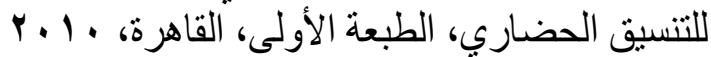

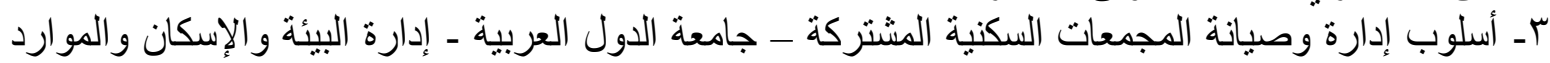

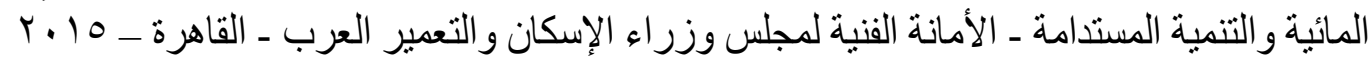

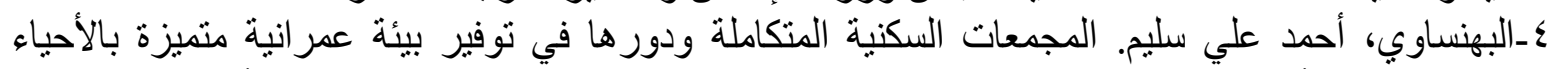

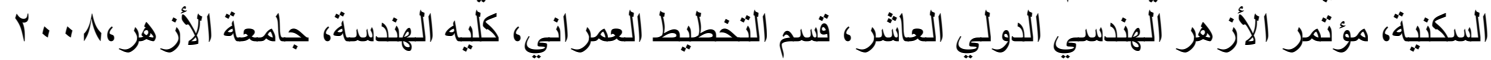

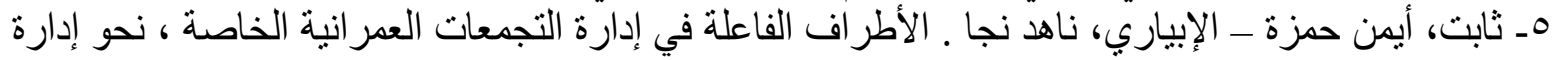

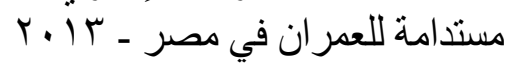

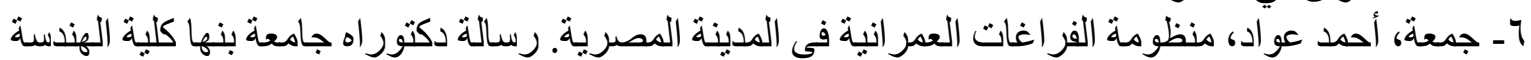

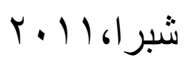

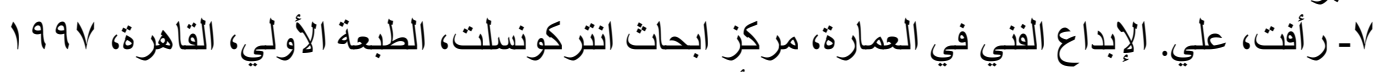

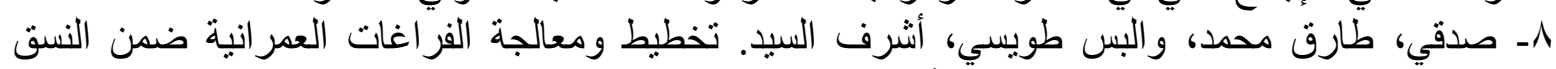

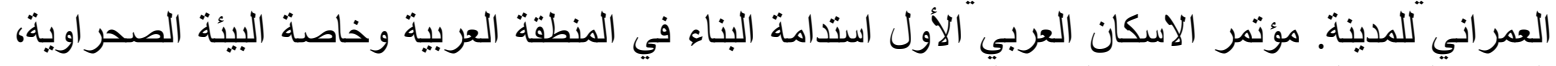

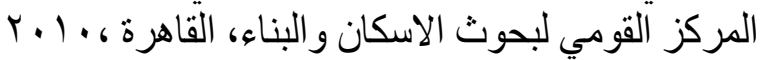

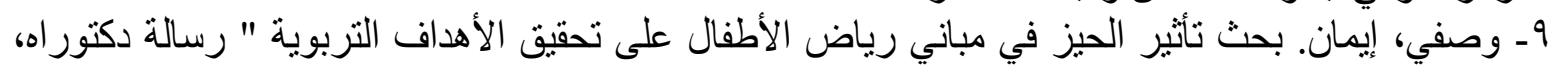

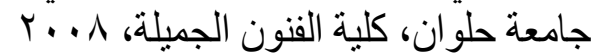
10-Banerjee. The Future of Public Space. Beyond Invented Streets \& Reinvented Place Journal of the American Planning Association U.S.A. Vol. 67, N.1, 2001 
11-Carmona, M \& others. Public Spaces - Urban Spaces. Second Edition, Architectural Press, Great Britain, 2010

12-Kevin Lynch, the Image of the City, Seventh Press, 1990, P, 420

13- Gehl, J, and Gemzoe, L, New City Spaces, Copenhagen, the Danish Architecture Press, 2000.

14-Youshinobu, Ichihara, Exterior design in architecture, Van No strand Reinhold, 1988. 